Chapman University

Chapman University Digital Commons

ESI Working Papers

Economic Science Institute

2011

\title{
Reaction to Public Information in Markets: How Much Does Ambiguity Matter?
}

Brice Corgnet

Chapman University, corgnet@chapman.edu

Praveen Kujal

David Porter

Chapman University, dporter@chapman.edu

Follow this and additional works at: http://digitalcommons.chapman.edu/esi_working_papers

\section{Recommended Citation}

Corgnet, B., Kujal, P., \& Porter, D. (2011). Reaction to public information in markets: How much does ambiguity matter?. ESI Working Paper 11-01. Retrieved from http://digitalcommons.chapman.edu/esi_working_papers/107

This Article is brought to you for free and open access by the Economic Science Institute at Chapman University Digital Commons. It has been accepted for inclusion in ESI Working Papers by an authorized administrator of Chapman University Digital Commons. For more information, please contactlaughtin@chapman.edu. 


\title{
Reaction to Public Information in Markets: How Much Does Ambiguity Matter?
}

\author{
Comments \\ Working Paper 11-01
}




\title{
Reaction to Public Information in Markets:
}

\section{How Much Does Ambiguity Matter?}

\author{
Brice Corgnet \\ Business Department \\ Universidad de Navarra \\ Praveen Kujal \\ Department of Economics \\ Universidad Carlos III de Madrid \\ David Porter \\ Economic Science Institute \\ Chapman University
}

\begin{abstract}
:
In real world situations the fundamental value of an asset is ambiguous. Recent theory has incorporated ambiguity in the dividend process and the information observed by investors, and studied its effect on asset prices. In this paper we experimentally study trader reaction to ambiguity when dividend information is revealed sequentially. Price changes are consistent with news revelation regarding the dividend regardless of subject experience and the degree of ambiguity. Further, there is no under or over price reactions to news. Regardless of experience, market reaction to news moves in line with fundamentals. Also, no significant differences are observed in the control versus ambiguity treatments regarding prices, price volatility and volumes for experienced subjects. Our results indicate that the role of ambiguity aversion in explaining financial anomalies is limited.
\end{abstract}

JEL Classification: G10, G12.

Keywords: Ambiguity, Dividend Revelation, Price Changes, Reaction to News, Experience 


\section{Introduction}

\section{I.1. Reaction to news in financial markets}

Recent research in behavioral finance has challenged the predictions of standard finance models putting forward the existence of financial anomalies such as the over- and under-reaction of asset prices to news. In their classic study, DeBondt and Thaler (1985) show price over-reaction to information where price movements exhibit disproportional changes followed by subsequent reversions. Jegadeesh and Titman (1993), meanwhile, conjecture that markets under-react to information about the short-term prospects of firms but overreact to information about their long-term prospects. ${ }^{1}$ In an attempt to summarize the literature, Shefrin (2000) points out that over-reaction tends to occur at very short horizons, while under-reaction occurs at long horizons. These empirical results contrast with Fama's (1998) claim that “apparent over-reaction of stock prices to information is as common as under-reaction."

These results have led to the development of alternative models that reproduce some of these anomalies. Incorporating cognitive biases, behavioral theories have shown the presence of under-and over-reaction in asset prices. In particular, Daniel, Hirshleifer, and Subrahmanyam (1998) examine investor overconfidence bias in how traders incorporate new information in their decision calculus. Based on evidence from psychological studies, the authors consider that traders overestimate their ability to collect precise information. This results in under-reaction to public, and over-reaction to private, information. Barberis, Shleifer and Vishny (1998) apply the conservatism and representative bias (i.e. new information is underweighted in updating) to investor decisions. Slow information updating of prior beliefs results in price under-reaction to new information. Over-reaction occurs as a result of the "representativeness bias" by which traders extrapolate trends in asset prices from very small samples of observations. Frazzini (2006), meanwhile, proposes that the presence of the "disposition effect", defined as the tendency of investors to ride losses and realize gains, depresses prices as traders try to lock in gains. In addition, a reluctance to sell at a capital loss allows prices

\footnotetext{
${ }^{1}$ This is actually motivated by the fact that the nature of the information available about a firm's short-term prospects, such as earnings forecasts, is different from the nature of the more ambiguous information that is used by investors to assess a firm's longer-term prospects.
} 
to hold steady on bad news. Prices thus exhibit under-reaction due to this psychological bias.

\section{2 Ambiguity in Finance Theory}

Standard finance theory has mostly assumed that the probabilistic structure of the process driving the fundamental value of financial assets is known. However, a substantial literature dating back to Ellsberg (1961) has shown that ambiguity about the probability of occurrence of lottery outcomes may significantly reduce the value assigned to a lottery. Recent literature has incorporated ambiguity regarding the stochastic process that determines the fundamental value of an asset in Finance models. This literature follows a different route, instead of bringing multiple psychological biases into the analysis it considers whether ambiguity may reproduce some of the financial anomalies. Three recent papers Leippold, Trojani and Vanini (2008), Ju and Miao (2009), and Ui (2010) account for the equity premium puzzle (Campbell and Cochrane, 1999) by introducing ambiguity in otherwise standard asset pricing models. ${ }^{2}$ Furthermore, ambiguity aversion has also been considered in order to account for the equity home bias by which traders under-invest in foreign assets (see Epstein and Miao (2003) and Myung (2009)).

Besides considering ambiguity in the dividend process, recent research has also considered the possibility of ambiguous information (Leippold, Trojani and Vanini (2007), Epstein and Schneider (2008), Caskey (2009)). Epstein and Schneider (2008) are able to account for the equity premium in a simple asset pricing model in the presence of ambiguous information. Investors take the worst-case approach to new information reacting more towards bad, than good, news. Such behavior produces an ambiguity premium on these types of assets. Further, Leippold, Trojani and Vanini (2007) show that asset prices react more strongly to bad, news than to good (news). Caskey (2009) has emphasized that ambiguity-averse traders are eager to favor information that reduces

\footnotetext{
${ }^{2}$ These models build on the seminal work of Epstein and Wang (1994).
} 
ambiguity at the cost of ignoring valuable pieces of information. As a result, asset prices may depart from fundamental values.

\section{I.3. Experimental Asset Markets and Ambiguity}

The complexity of modeling uncertainty in real market settings points towards the difficulty faced by researchers in testing the existence of ambiguity aversion when first and second order individual beliefs are not observable. In this context, experiments offer a possible solution as they allow the experimenter to control for uncertainty. For example, some experiments have controlled for uncertainty following a procedure similar to Ellsberg (1961). Subjects play a lottery that consists in drawing a ball from one of the two urns. The number of balls and their color is known in one urn while the color composition is unknown in the other urn. In line with Ellsberg, some authors have stressed the presence of significant ambiguity aversion (Yates and Zukowski (1976), Curley and Yates (1985), Cohen, Tallon and Vergnaud (2009)). Meanwhile, others have argued that ambiguity aversion can be dampened, or even eliminated, if ambiguous and unambiguous lotteries are evaluated separately (Fox and Tversky (1995), Chow and Sarin (2002)). Camerer and Weber (1992) and Du and Budescu (2005) have stressed that ambiguity aversion is more significant in gains than in losses. ${ }^{3}$

Experimental results to date with state ambiguity show lower prices due to ambiguity aversion. In Sarin and Weber (1993) ambiguity aversion is reflected in reduced asset prices in a sealed bid and a double auction. Their result is particularly strong when the ambiguous and the unambiguous assets are traded simultaneously. Bossaerts et al. (2010) also report significant effects of ambiguity in experimental asset markets with portfolio choices. Their results are in line with theory (Dow and Werlang (1992), Mukerji and Tallon (2001)) stressing that when some state probabilities are not known, agents who are sufficiently ambiguity averse may refuse to hold an ambiguous portfolio for a certain range of prices.

\footnotetext{
${ }^{3}$ In addition, at the brain level Smith et al. (2002) have reported ambiguity aversion in gains while no ambiguity attitudes were identified in the domain of losses.
} 
In this paper, we consider whether the introduction of ambiguity may reproduce some of the anomalies that have been documented regarding asset price reaction to news. In this respect our research fits with the argument that a possible account for financial anomalies can be the existence of un-modeled risk factors (such as ambiguity) that can be interpreted as an additional factor regarding the evaluation of risk.

We use Ellsberg's procedure to introduce ambiguity in an experimental asset market where public information is sequentially released to traders. Our experimental design allows us to study how individual traders react to news in a context in which they receive information regarding dividend realizations. In our experiments, either the underlying process that generates dividends comes from a known probability distribution or is ambiguous. We can analyze the reaction to public information in an ambiguous environment since we are able to control for the level of ambiguity of the asset by specifying the stochastic process that generates dividend values.

In the baseline experiment, the probability distribution of dividends is publicly known, and subjects are informed that the dividend realization may be drawn from two different regimes with high and low values, respectively. Subjects are aware about the two different regimes and are told the actual regime at the end of the first period. Given the information, subjects then trade in period two. At the end of the second trading period, participants are informed which of the dividends in the announced (dividend) regime will not be realized. The final dividend is realized at the end of period three. In the ambiguity treatment, the probability of occurrence of the two different dividend regimes is left unknown. Specifically, we tell subjects that a given regime of dividends will be selected at the end of the first period of trading by drawing a marble of a certain color from an opaque bag containing colored marbles with unknown quantities and proportions. Given that it has been shown that experience can be relevant in understanding trading behaviors in experimental asset markets (Smith, Suchanek and Williams (1988), Lei, Noussiar and Plott (2001), Dufwenberg, Lindqvist and Moore (2005)) we repeat the experimental sessions so as to control for the effect of experience.

\section{I.3. Hypotheses}


Our design enables us to study how ambiguity regarding the fundamental value of an asset affects trader reaction to public news. Furthermore, we can also study how ambiguity is reflected in market variables such as prices, price volatility and trading volumes. We test the following hypotheses that are motivated by both the empirical and theoretical literature in Finance and ambiguity aversion previously mentioned. Our first hypothesis relates to research showing ambiguity aversion in the domain of gains in a lottery context (Ellsberg (1961), Yates and Zukowski (1976), Curley and Yates (1985), Cohen, Tallon and Vergnaud (2009)) and experimental markets (Sarin and Weber, (1993)).

Hypothesis 1: Regardless of subject experience, we expect asset prices to exhibit an ambiguity premium. That is, average asset prices under the ambiguity treatment are expected to be lower than the baseline treatment.

Our second hypothesis is related to theoretical results that predict that ambiguity can lead to inertia in trading behavior and reduce trading volumes, as result (Dow and Werlang 1992, Mukerji and Tallon, (2001)). Further, due to the indeterminacy in equilibrium prices (that may leave the determination of asset price equilibria to animal spirits) asset price volatility is expected to rise in the presence of ambiguity (Epstein andWang 1994). This leads us to the following hypothesis.

\section{Hypothesis 2:}

i) Regardless of subject experience, we expect ambiguity to increase volatility in asset markets (Epstein and Wang, 1994).

ii) Regardless of subject experience, we expect ambiguity to reduce trading volumes in asset prices (Dow and Werlang 1992, Mukerji and Tallon 2001).

In terms of reactions to news, we examine the following hypothesis.

\section{Hypothesis 3:}

i) Regardless of subject experience, asset prices in both the baseline and the ambiguity treatments increase (decrease) after good (bad) news is released. 
ii) Regardless of subject experience, asset prices in both the baseline and the ambiguity treatments do not exhibit either under- or over-reaction to news.

Notice that Hypothesis 3 ii) relies on Fama's conjecture that, regardless of the treatment, reaction to news should be consistent with news content and exhibit neither under- nor over-reaction (Fama, 1998).

In contrast with the existing literature that considers lottery choices we find the absence of any ambiguity premium in asset prices. Surprisingly, inexperienced subjects generate prices closer to fundamental value relative to the baseline treatment in the ambiguity treatment. Also, we do not observe a reduction of trading volumes (Dow and Werlang (1992) and in Mukerji and Tallon (2001)). We confirm the increased volatility predicted by Epstein and Wang (1994), however. In addition, the absence of significant differences in the reaction to public news (between the baseline and the ambiguity treatment in the case of experienced subjects) confirms the limited role of ambiguity in our experimental asset markets. We find support for Fama's assertion that over-reaction should be as common as under-reaction. Reaction to news is in line with fundamentals in both treatments, regardless of subject experience.

\section{Experimental design}

Six sessions were run in both treatments. In each session the market was repeated. This gives us a total of 24 market observations (12 for the baseline and 12 for the ambiguity treatments). Subjects were recruited from an undergraduate student subject pool at a major US university. Subjects were randomly selected across gender and majors.

Each experimental session had eight traders. Initial portfolios were structured so that three traders were endowed with 450 cents in cash and 3 shares, two with 600 cents in cash and 2 shares while, the remaining three traders were endowed with 750 cents in cash and 1 share. Each session consisted of three trading periods lasting 4 minutes each. Information concerning the possible per share dividend was released at the end of the first and second trading periods. At the end of the third trading period, a final dividend was announced and participant profits were given according to the final cash position plus 
dividends earned. Each experiment began with a short practice session to allow everyone to become familiar with the trading interface and process. Subjects were informed that the final dividend would be selected from one of two sets: $\{50,100,150\}$ or $\{100,200$, $300\}$. Dividend values were expressed in cents. The baseline treatment was conducted as follows.

At the end of the first trading period a subject was selected at random to flip a coin. If the coin came up heads, the dividend was selected from $\{50,100,150\}$. If it was tails, the dividend came from $\{100,200,300\}$. Trading then proceeded to periods 2 and 3. At the end of the second trading period a subject was selected to roll a die. If numbers 1 or 2 were rolled then the dividend would NOT be the low number in the range. If numbers 3 or 4 were rolled the dividend would NOT be the middle number in the range. If numbers 5 or 6 were rolled the dividend would NOT be the high number in the range. Note that, this procedure further reduces the dividend uncertainty subject's face. Trade was then open for period 3. When period 3 ended, a subject flipped a coin to determine the dividend from the two remaining dividends. If the flip was heads the dividend was the lower of the two dividends and if it was tails the higher dividend was used.

Instructions for these experiments can be found in Appendix A. The experiment was repeated with the same cohort of traders and with the same procedures. ${ }^{4}$ Earnings were paid in cash at the end of the second experimental session.

In the ambiguity treatment, each session used five separate opaque bags containing colored marbles. The quantities and proportions of marbles in each bag were left unknown. All bags were placed in the front of the room prior to subjects entering the lab, and remained in subject view during the entirety of the experiment. The marble composition of the bags was as follows.

- Bag 1: Light Blue and Dark Blue

- Bag 2: Red, Yellow, and Green

- Bag 3: Red and Yellow

\footnotetext{
${ }^{4}$ We did not inform subjects at the beginning of the experiments that there would be a replication of the market. The replication was announced at the end of the first market run.
} 
- Bag 4: Yellow and Green

- Bag 5: Red and Green

Before starting the first period of trading, a subject was selected to flip a coin and another to roll a die. The result of the coin toss was announced to everyone by the subject and this determined whether the Light Blue marbles in Bag 1 represented the high $\{100$, $200,300\}$, or the low set of dividends $\{50,100,150\}$. The result of the die roll was also announced. This determined what color marble (Red, Yellow, or Green) in Bag 2 represented which dividend level (high, medium or low). This procedure avoided subject suspicion regarding possible attempts of the experimenter to select the value of marbles that would minimize the cost of the experiment.

Each time subjects flipped a coin, roll a die or draw a marble, the experimenter wrote the corresponding information on a white board located above the marble bags. Both the white board and the marble bags were visible to the eight subjects in the session. Without any further information subjects then traded the asset in period 1 .

At the end of period 1, a subject was chosen to draw a marble from Bag 1. Without being able to observe the contents of the bag, the subject drew a marble and announced it to everyone. Subjects were informed again that the final dividend would be selected from the set associated with the color drawn. Subjects now traded assets in period 2.

After period 2 was completed, a different subject was again chosen to draw a marble from Bag 2. Again, without being able to observe the contents of the bag, the subject drew a marble and announced it to everyone. Subjects were then informed that the final dividend would NOT be the value associated with the color drawn. Subjects now traded in period 3 .

At the end of period 3, a different subject was chosen to draw a marble from Bag 3, 4 or 5 depending on the color of the marble drawn from Bag 2. If the marble drawn from Bag 2 was Green (Red) [Yellow] then the subject used the bag with the two remaining colored marbles, that is, Bag 3 (Bag 4) [Bag 5]. 
Without being able to observe the contents of the bag, the subject drew the final marble and announced it to everyone. The dividend value for this session was the value associated with the marble drawn.

As in the baseline, subjects were then informed that they were going to repeat a new market. The five bags used in the first experimental session were then replaced by the experimenter. In full view of the subjects the experimenter placed the old bags on the floor and the new ones on the table. As a result, no learning about the composition of the bags used in the first market could occur in the replication market.

To ensure subjects understood the process, the experimenter went through a practice run inviting subjects to flip a coin, roll a die and draw marbles before each experiment actually started. In the practice round, the experimenter completed a full sequence of draws in which the value of the marbles was determined first by flipping a coin and rolling a die. This was followed by the selection of the regime of dividends (Bag 1), the release of dividend information (Bag 2) and the selection final dividend (Bag 3, 4 or 5). The experiment was repeated with the same cohort of traders and with the same parameters $^{5}$. Each experiment lasted 1-1/2 hours. On completion of the experiment subjects were called up individually to be paid their private earnings from both sessions plus a $\$ 7$ dollar show up fee. Average earnings for both the ambiguity and the baseline sessions were $\$ 24.80$.

\begin{tabular}{|l|l|l|}
\hline \multicolumn{2}{|c|}{ Table 1: Experimental Design Summary } \\
\hline Number of traders per session & Endowment & Trading mechanism \\
& & \\
\hline
\end{tabular}

\footnotetext{
${ }^{5}$ Instructions for the ambiguity treatment can be found in Appendix A.
} 


\begin{tabular}{|c|c|c|}
\hline $\begin{array}{c}8 \text { traders for each of the } 12 \text { experimental } \\
\text { sessions ( } 6 \text { baseline sessions and } 6 \\
\text { ambiguity sessions) with a repetition }\end{array}$ & $\begin{array}{l}3 \text { subjects with } 450 \text { cents in } \\
\text { cash and } 3 \text { shares } \\
2 \text { subjects with } 600 \text { cents in } \\
\text { cash and } 2 \text { shares } \\
3 \text { subjects with } 750 \text { cents in } \\
\text { cash and } 1 \text { share }\end{array}$ & $\begin{array}{l}\text { Continuous double } \\
\text { auction mechanism } \\
\text { with four-minute } \\
\text { trading periods. }\end{array}$ \\
\hline
\end{tabular}

\section{Experimental Results}

In the first subsection, we compare the baseline and the ambiguity treatments. We look at aggregate market measures such as average asset prices, volatility, and trading volumes. This is followed by an analysis of trader reaction to news to public information released in periods 2 and 3. Finally, we analyze subjects' individual trading behavior.

\section{III.1. Aggregate analysis: Asset prices, Volatility and Trading volumes}

We first look at average asset prices in the first period of trading in the baseline and ambiguity treatments. In the baseline treatment the two dividend distributions, $\{50,100$, $150\}$ and $\{100,200,300\}$ are equally likely. Meanwhile, in the ambiguity treatment subjects are unaware of the likelihood of occurrence of each regime. Note that, no public news has been released in the first period of trading. Thus, any difference in asset prices, volatility or trading volumes across the treatments can be attributed to the existence of ambiguity (i.e. in the likelihood of occurrence of dividend regimes) as long as subjects hold a uniform prior distribution over dividend values. ${ }^{6}$ This is, however, not the case in periods 2 and 3, since information about the regime is released in the second period while information about dividends is released in the third period. As a result, differences in asset prices, volatility or trading volumes in periods 2 and 3 between treatments cannot

\footnotetext{
${ }^{6}$ If subjects hold different priors regarding the likelihood of occurrence of marbles colors, then our statement would still be correct on average for a large sample of subjects. Given that subjects do not possess any prior information about the distribution of marbles colors in the experimenter's bags, the conjecture that subjects hold a uniform prior distribution over marbles colors appears to be reasonable. This argument relies on the principle of indifference put forward by early probabilists like Jacob Bernouilli or Pierre Simon Laplace.
} 
be uniquely attributed to ambiguity effects. If observed, the differences could also be a consequence of the release of public information, as well as any interaction effect between ambiguity and trader reaction to news.

We start by testing Hypothesis 1 regarding the existence of an ambiguity premium in asset prices for inexperienced subjects.

Result 1: For inexperienced subjects, relative to baseline experiments, average contract prices in the first period are significantly higher in the ambiguity treatment. With experienced subjects, first-period average asset prices are not significantly different between the two treatments. We find no evidence of an ambiguity premium in our environment.

Support: Table 2 shows that first-period average asset prices are significantly lower than the fundamental value of 150 in the baseline treatment. ${ }^{7}$ Interestingly, asset prices are not significantly different from the fundamental value in the ambiguity treatment. It seems that subjects disregard probabilities and average out the five possible dividend values (50, $100,150,200,300){ }^{8}$ For inexperienced subjects, average asset prices under the ambiguity treatment (165.2) are significantly greater (Wilcoxon Rank Sum test, p-value = $0.0649)$ relative to the baseline (118.7). ${ }^{9}$

Our result contrasts with experimental studies that have emphasized the existence of an ambiguity premium in experimental asset markets (Sarin and Weber, (1993)). However, one should point out that the results in Sarin and Weber (1993) are obtained when ambiguous and unambiguous assets are traded simultaneously. We find that the ambiguity premium is not observed if ambiguous and unambiguous assets are not traded

\footnotetext{
${ }^{7}$ In Appendix B, we provide an analysis of asset prices for periods 2 and 3. For further periods, each experimental session is characterized by different fundamentals so that we analyze average mispricing measures instead of average asset prices. Our basic results are confirmed in the sense that no ambiguity premium appears whether we consider inexperienced or experienced subjects. We also display the time series of contract prices for all sessions.

${ }^{8}$ A one-sided Wilcoxon Rank Sum test with alternative hypothesis: median asset prices are greater than 150 [160] leads to a p-value equal to 0.103 [0.173].

${ }^{9}$ Average asset prices are below the expected dividend value in the baseline suggesting the typical riskaversion pattern of asset prices found in experimental asset markets (Smith, Suchanek and Williams (1988), Lei, Noussair and Plott (2001)).
} 
simultaneously. The most intriguing part of our result is that, compared to the baseline treatment, average asset prices for inexperienced subjects are significantly higher in the ambiguity treatment. This could be an indication of the presence of animal spirits as is suggested in Epstein and Wang (1994). To quote Shiller (2000, p137): "in ambiguous situations people's decisions are affected by whatever anchor is at hand". This may make it difficult to predict asset prices in the presence of ambiguity. However, average asset prices do not significantly differ between the ambiguity and baseline treatments for experienced subjects (see table 2).

\begin{tabular}{|c|c|c|}
\hline \multicolumn{2}{|c|}{ Table 2: Comparison of first-period average (median) asset prices: } \\
\multicolumn{2}{|c|}{ Ambiguity vs. Baseline } \\
\hline Baseline & $118.7(109.5)$ & Experienced subjects \\
\hline Ambiguity & $165.2(180.2)$ & $156.2(160.7)$ \\
\hline \multicolumn{2}{|c|}{ Wilcoxon two-sided Rank Sum test (p-value) } \\
\hline Mean (Median) prices & p-value $=0.0649(0.0198)$ & p-value $=0.8182(0.6879)$ \\
Baseline vs. Ambiguity & Baseline & \\
\hline Null hypothesis: & p-value $=0.0938(0.0452)$ & p-value $=0.6875(0.5625)$ \\
Mean asset price $=150$. & Ambiguity & Ambiguity \\
Alternative hypothesis: & p-value $=1.000(0.2463)$ & p-value $=0.4375(0.8326)$ \\
\hline Mean asset price $\neq 150$. &
\end{tabular}

Turning to Hypothesis 2i), Epstein and Wang (1994) suggest that ambiguity may result in increased volatility of asset prices. We find:

Result 2: For inexperienced subjects, compared to the baseline treatment, the standard deviation of contract prices in the first period is significantly higher in the ambiguity treatment. With experienced subjects, first-period standard deviation of contract prices is not significantly different between the two treatments.

Support: Relative to the baseline, the presence of ambiguity increases volatility in asset prices by more than $73 \%$. Table 3 shows the standard deviation of prices in period 1 . 
Notice that the standard deviation of asset prices in the first period sharply decreases with experience in the ambiguity treatment. Actually, standard deviation is not significantly different between the ambiguity and baseline treatments for experienced subjects.

\begin{tabular}{|c|c|c|}
\hline \multicolumn{2}{|c|}{ Table 3: Comparison of first-period asset prices standard deviation: } \\
\cline { 2 - 3 } & Ambiguity vs. Baseline \\
\hline Baseline & 36.79 & Experienced subjects \\
\hline Ambiguity & 63.69 & 26.94 \\
\hline \multicolumn{2}{|c|}{ Mean comparison: Baseline vs. Ambiguity treatments } \\
\hline $\begin{array}{c}\text { P-values: Wilcoxon two-sided [one- } \\
\text { sided] Rank Sum tests }\end{array}$ & p-value = 0.132 [0.066] & p-value $=0.937[0.591]$ \\
\hline
\end{tabular}

Note that a general analysis of volatility requires controlling for the underlying fundamental value of the asset in each experimental period of each experimental session. To that end, we use the dispersion ratio measure proposed by Palan (2009). The dispersion ratio in period $t$ is defined as the sample ratio of asset prices in period $t$ divided by population standard deviation of the fundamental value of the asset in the same period. This allows us to compare across sessions and periods with different underlying fundamental values.

In the following regressions we assess the treatment effect on asset price volatility in periods 2 and 3, respectively. We control for the treatment by introducing a dummy that takes value one for ambiguity sessions and zero otherwise. We show that, regardless of experience, ambiguity does not affect volatility significantly in periods 2 and 3 . The dummy variable for treatment is not statistically significant in any of the regressions displayed in table 4. This finding rejects Hypothesis $2 i$ ). However, one has to be cautious in the interpretation of these results. The effect of ambiguity, or its absence, can be confounded with the effect, or lack of it, of the release of public information in periods 2 and 3. Notice that in the regression results of table 4, dispersion ratios in a given period depend positively on the previous period dispersion ratio for inexperienced traders. This positive relationship, however, does not hold in the case of experienced subjects. 


\begin{tabular}{|c|c|c|c|c|}
\hline \multicolumn{5}{|c|}{ Table 4: OLS estimates for inexperienced and experienced traders ${ }^{10}$} \\
\hline \multicolumn{5}{|c|}{ Dependent variables: Dispersion Ratio ${ }^{11}$} \\
\hline Coefficients & Dispersion $\mathrm{R}$ & tio Period 3 & Dispersion & o Period 2 \\
\hline (P-values) & Inexperienced & Experienced & Inexperienced & Experienced \\
\hline Intercept & -0.61 & 28.46 & 7.74 & 20.73 \\
\hline Treatment & -0.40 & 7.65 & -3.07 & -10.91 \\
\hline $\begin{array}{c}\text { Dispersion } \\
\text { Ratio Period } 2\end{array}$ & $0.96^{* * *}$ & -0.28 & - & - \\
\hline $\begin{array}{c}\text { Dispersion } \\
\text { Ratio Period } 1\end{array}$ & -0.10 & -0.12 & $0.50 * *$ & 0.30 \\
\hline R squared & 0.72 & 0.08 & 0.54 & 0.28 \\
\hline
\end{tabular}

Recall that according to Hypothesis 2ii), regardless of experience, trading volumes are expected to be lower in the ambiguity sessions (Dow and Werlang 1992, Mukerji and Tallon 2001).

Result 3: Regardless of subject experience, trading activity is not significantly different between the ambiguity treatment and the baseline.

Support: Regardless of subject experience, trading volumes across the baseline (26) and the ambiguity treatment (26.8) are similar. Despite increased asset prices and standard deviation in the first period, ambiguity sessions do not generate significant differences in trade volumes. Table 5 presents the average volumes for the two treatments. ${ }^{12}$

\footnotetext{
${ }^{10}$ The OLS regressions presented in the analysis passed the Jarque-Bera Normality test. In addition, we also control for heteroskedasticity by using White standard errors.

${ }^{11}$ We consider standard statistical significance levels of $1 \%, 5 \%$ and $10 \%$. Significance at these levels are indicated in the regression table by the respective symbols $* * *, * *$ and $*$.

${ }^{12}$ Our results are similar to experimental asset markets that show that trading volumes decrease with experience (Smith, Suchanek and Williams (1988), Lei, Noussair and Plott(2001)). We test this hypothesis using a Wilcoxon one-sided Rank Sum test and we obtain a p-value of 0.014 for the aggregate sample (ambiguity and baseline sessions are pooled) and p-values of 0.074 and 0.063 for the baseline and ambiguity treatments, respectively.
} 


\begin{tabular}{|c|c|c|}
\hline \multicolumn{2}{|c|}{ Table 5: Comparison of first-period (total) trading volume: } \\
& Ambiguity vs. Baseline \\
\hline Bnexperienced subjects & Experienced subjects \\
\hline Ambiguity & $26(62.2)$ & $14.3(31.2)$ \\
\hline $\begin{array}{c}\text { P-values: Wilcoxon two-sided Rank } \\
\text { Sum tests } \\
\text { (Mean comparison between Baseline } \\
\text { and Ambiguity treatments) }\end{array}$ & $26.8(56)$ & $15.8(32.8)$ \\
\hline
\end{tabular}

In the next subsection we test Hypothesis 3 and analyze trader reaction to public news (released in periods 2 and 3 ).

\section{III.2. Reaction to News}

The main purpose of our experimental design is to analyze reaction to news in asset markets with and without ambiguity. We conduct our analysis in two parts. We first focus on the direction of price changes (Hypothesis $3 i$ ) and then we study its magnitude (Hypothesis 3ii). We first analyze whether price changes are consistent with the release of either good or bad news before analyzing the possibility of under-, or over-, reaction to public news.

\section{III.2.1. Direction of price changes}

We study reaction to news by first looking at the direction of price changes following the release of public news. Any piece of news that increases (decreases) the expected value of dividend streams associated with the asset is classified as "good news" ("bad news"). We develop a simple ordinal measure of the direction of price changes with respect to the news received by traders in periods 2 and 3 . We classify the evolution of average contract prices in period $t\left(P_{t}\right)$ as follows. 
Definition 1: (Consistent price changes) If $P_{t}-P_{t-1}>0\left[P_{t}-P_{t-1}<0\right]$ for $t \in\{2,3\}$, then a change in average prices in period $t$ is consistent with the release of good [bad] news in period $t \in\{2,3\}$. $^{13}$

\section{Result 4: (Consistent price changes)}

i) The proportion of consistent average price changes is not significantly different between the ambiguity and the baseline treatments. This is true regardless of subject experience.

ii) Compared to experienced subjects, the proportion of consistent price changes is not significantly different for inexperienced subjects.

iii) The proportion of consistent price changes is not significantly different between periods 2 and 3.

Support: We display the information on consistent price changes across treatments and periods in table 6 .

\begin{tabular}{|c|c|}
\hline \multicolumn{2}{|c|}{ Table 6: Proportion of consistent price changes in periods 2 and 3: } \\
Inexperienced [experienced] traders (by treatments and periods) \\
\hline Baseline & $6 / 8[8 / 9]$ \\
\hline Ambiguity & $8 / 9[6 / 9]$ \\
\hline Inexperienced vs. experienced & $14 / 17[14 / 18]$ \\
\hline
\end{tabular}

We observe a very-high proportion of consistent price changes both in the baseline (82.4\%) and the ambiguity treatment (77.8\%). A Chi-squared proportions test tells us that the (proportions) are significantly different from 50\% (p-values of 0.012 and 0.031, respectively). Subjects in experienced sessions exhibit a greater consistency levels

\footnotetext{
${ }^{13}$ Notice that, at the end of period 2 the information delivered to subjects may be neutral. In this case we should not expect price changes. Definition 1 restricts our analysis to the case in which either bad or good news is released before the start of period 3. This is the reason why the number of price changes in period 3 considered for inexperienced and experienced sessions is only equal to five and six (table 6), respectively. A separate analysis of neutral news is available upon request. In particular, we do not find any significant differences in the reaction of asset prices with respect to neutral news across treatments.
} 
in price changes $(82.4 \%$ vs. $77.8 \%$ for inexperienced). This difference in proportions is, however, not significant $(\mathrm{p}$-value $=0.7352)$.

In table B.1 (appendix), we summarize the rest of our results comparing the proportion of consistent price changes among treatments, periods, and levels of experience. We find that levels of consistent price changes are not significantly different across treatments, periods or, levels of experience. In particular, the presence of ambiguity does not preclude inexperienced traders from reacting consistently to news. Interestingly, reaction to public information in the ambiguity sessions, far from being indeterminate and subject to possible animal spirits, is consistent with the news released. This tells us that, in the context of ambiguity, the release of information may lead to consistent reactions as it reduces ambiguity. In the absence of a determinate equilibrium in contract prices, following Shiller's argument, one can think of public news as a benchmark for trading. Our results on the consistency of contract prices changes are summarized in Result 5 below. We confirm Hypothesis 3i) under which we expect no differences in consistency of price changes across treatments and levels of experience.

Even though we do not observe significant differences in price change consistency across treatments and levels of experience at the aggregate level, we still need to verify whether the results are maintained for the individual analysis. To do this we first need to provide a measure of individual reactions to news released in period $t$. This can be done by assessing trader valuation of an asset in any given period $\left(V_{t}\right)$ and then measure the difference in the trader's valuation of the asset across periods $t-1$ and $t$. A natural definition of a trader's valuation of the asset in period $t$ has to depend on a (trader's) offers to buy and sell in the given period. In particular, this valuation has to depend on the bid-ask spread. In the following definition we determine a trader's valuation of the asset as the midpoint of the average bid-ask spread. ${ }^{14}$

\footnotetext{
${ }^{14}$ We have used alternative measures of trader's valuation of the asset in period $t$ (such as average bids or average asks in period $t$ or last bid or ask in period $t$ ). Our results are maintained (summarized in Result 5) with these alternative measures.
} 
Definition 2: (Traders' valuation of the asset) Trader $i$ 's valuation of the asset in period $t$ is determined as an arithmetic average of trader $i$ 's bids and asks, that is, $V_{i, t}=$ $1 / 2 \times($ Average bid of trader $i$ in period $t+$ Average ask of trader $i$ in period $t)$.

We now identify correct trading responses to news in period $t$ when a trader's valuation increases (decreases) after the release of good (bad) news at the end of period $t-1$.

Definition 3: (Correct individual trading responses) If $V_{i, t}-V_{i, t-1}>0\left[V_{i, t}-V_{i, t-1}<0\right]$ for $t \in\{2,3\}$ then we consider that the trading response of individual $i$ in period $t$ is correct if good [bad] news has been released in period $t \in\{2,3\}$.

Result 5: (Individual trading responses to news)

Compared to the baseline, for inexperienced subjects the proportion of correct trading responses is significantly higher for the ambiguity treatment.

Support: We first compare the proportion of correct individual responses to news using proportion tests. This analysis is summarized in the following table.

\begin{tabular}{|c|c|c|c|}
\hline \multicolumn{4}{|c|}{ Table 7: Proportion of correct individual responses to news: } \\
Inexperienced [experienced] traders (by treatments and periods) \\
\hline & Period 2 & Period 3 & Total \\
\hline Baseline & $69.0 \%[92.1 \%]$ & $43.5 \%[88.2 \%]$ & $60.0 \%[90.9 \%]$ \\
\hline Ambiguity & $76.6 \%[90.0 \%]$ & $95.0 \%[47.4 \%]$ & $82.1 \%[76.3 \%]$ \\
\hline Aggregate & $73.0 \%[91.0 \%]$ & $67.4 \%[66.7 \%]$ & $71.2 \%[83.3 \%]$ \\
\hline
\end{tabular}

At the individual level we find significant differences in consistency of price changes across treatments and experience levels. A significant difference in the 
proportion of correct individual responses to news between inexperienced $(83.3 \%)$ and experienced subjects $(71.2 \%)$ is observed. ${ }^{15}$

It seems ambiguity leads to more accurate responses to news for inexperienced subjects $(82.1 \%$ vs. $60 \%$ in baseline). This difference is statistically significant (see table B.2 in the appendix). This result confirms that ambiguity leads to surprisingly accurate reactions to news both at the aggregate and the individual level. This (positive) effect of ambiguity is especially relevant given that experimental asset markets with news have been characterized by a high degree of inertia where subjects fail to fully adjust to news in a given period (Lin and Rassenti, 2010). The release of information in ambiguity sessions is particularly relevant for traders as it informs them about the fundamental value of the asset and reduces uncertainty about the intrinsic value of the asset at the same time. However, the positive effect of ambiguity on trading response accuracy diminishes with time. In the baseline treatment the proportion of correct trading responses increased from $60 \%$ to $90.9 \%$ with experience. In the ambiguity treatment, the proportion of correct trading responses does not increase. This is due to the fact that the proportion of these responses was already particularly high $(82.1 \%)$ in the first session with inexperienced subjects.

The sharp response to public information in the ambiguous markets is consistent with Caskey (2009) that stresses that ambiguity-averse traders are eager to reduce ambiguity. In our experimental design, traders may quickly respond to public information under the ambiguity treatment as they perceive that the release of public information reduces ambiguity in addition to reducing risk. ${ }^{16}$

Reaction to news in the two treatments is highlighted by looking at experimental sessions with inexperienced traders, a high regime of dividends and positive news, and another session in which the regime of dividends was low and the news negative. We observe that the reaction to news in both treatments moves in line with fundamentals (Figure 1a). At the end of each period, transaction prices are particularly close to the fundamental value. However, in the inexperienced session, with a low dividend regime

\footnotetext{
${ }^{15}$ The $\mathrm{p}$-value of the proportion test is equal to 0.030 .

${ }^{16}$ The release of information to subjects reduces the variance of the fundamental value of the asset and reduces risk, as a result. Ambiguity is also dampened in the sense that the number of possible dividend values (states of the world), each of them determined by an ambiguous probability, decreases.
} 
and bad news on dividends (Figure 1b), the baseline session is characterized by prices that do not move in the direction of the fundamental value. Meanwhile, the reaction of contract prices in the corresponding ambiguity session is correct and particularly fast.

Figure 1a: Baseline session (on the left panel) and ambiguity session (right panel) with high regime and good news

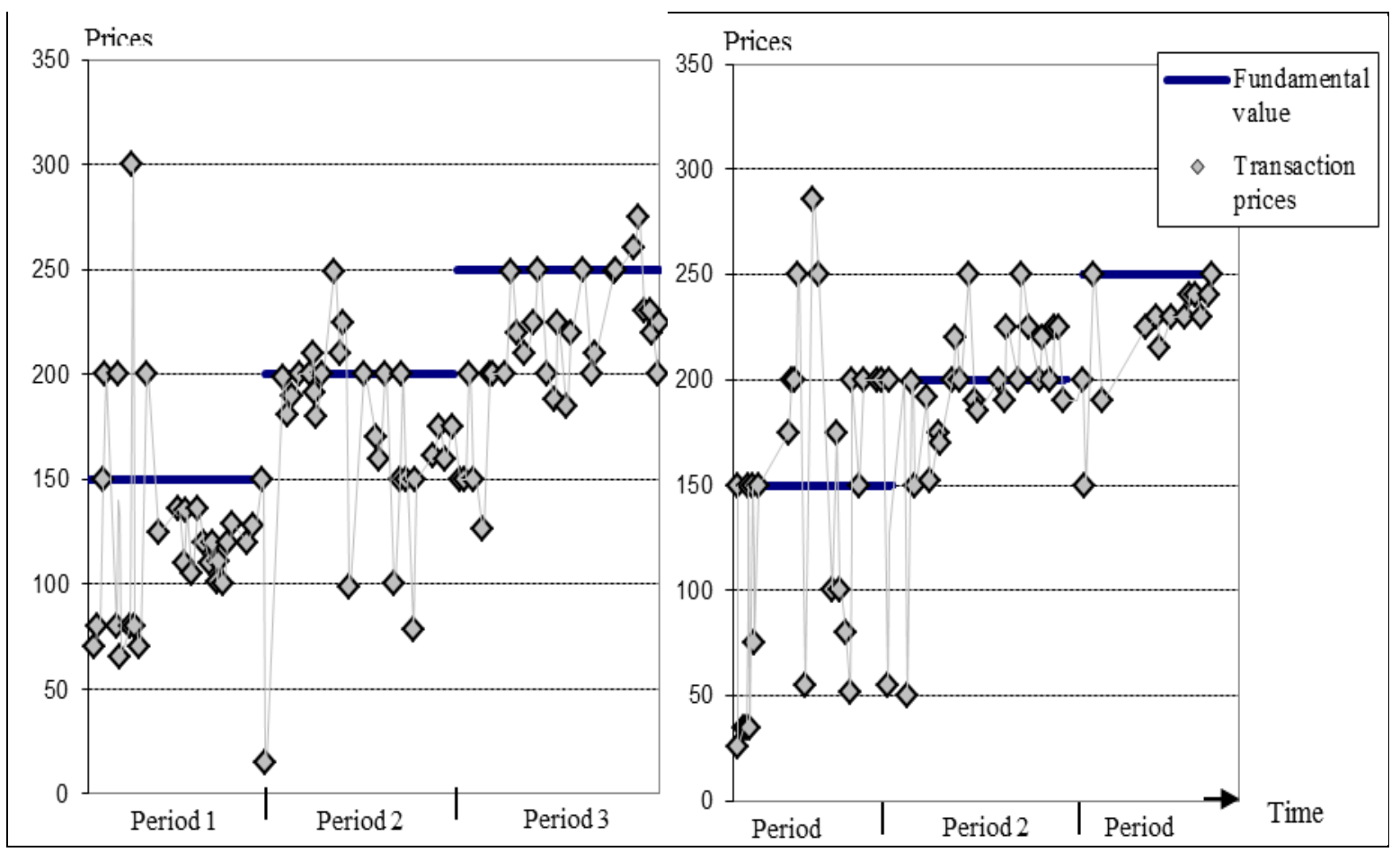

Figure 1b: Baseline session (on the left panel) and ambiguity session (right panel) with low regime and bad news
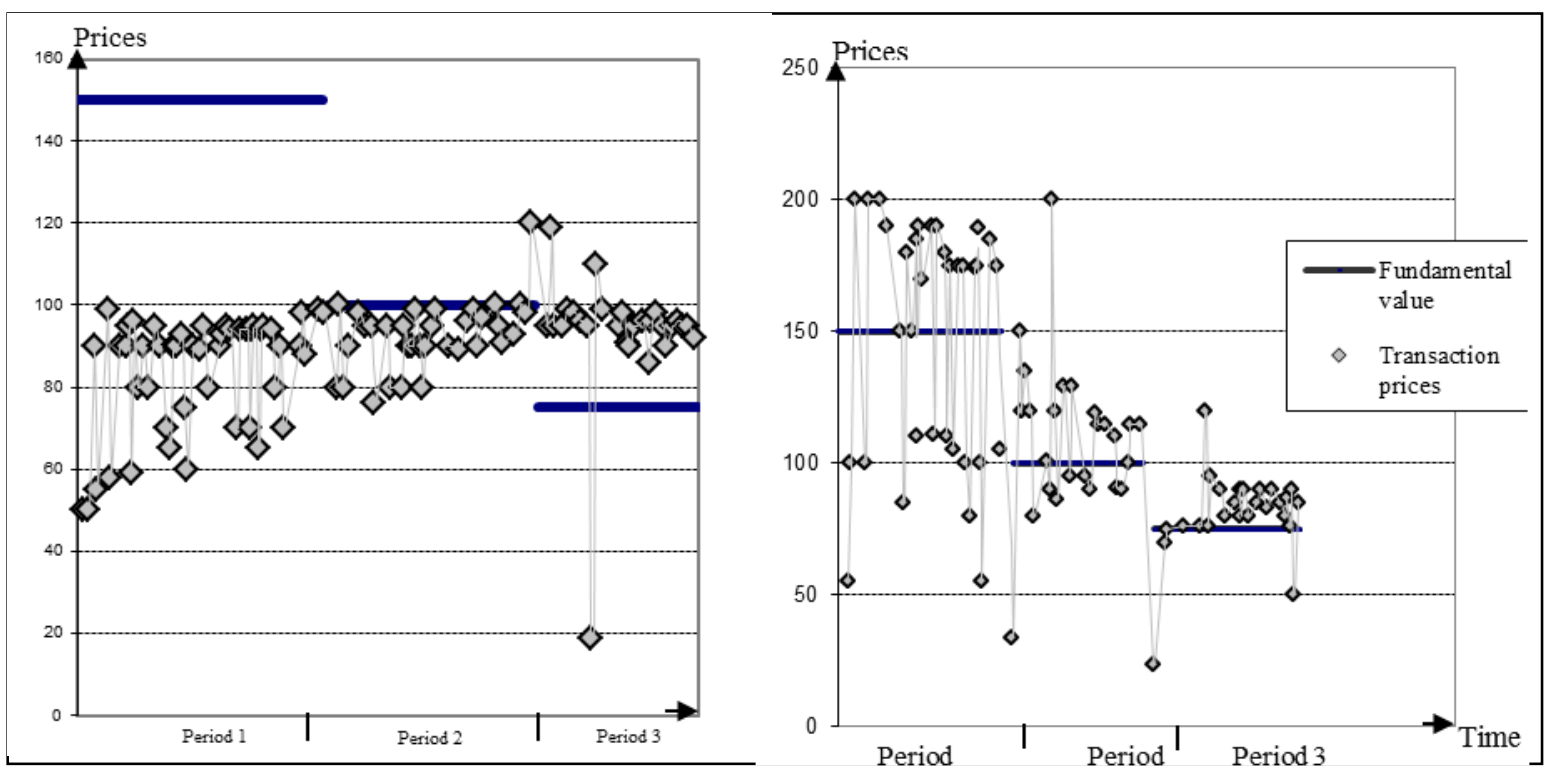
We confirm Result 3 by using regression analysis where we control for the news that is actually released in the different experimental sessions (see table B.3 for additional regressions). Indeed, whether the dividend regime is high or low or, the news in period 3 good or bad, affects the patterns of contract prices and trading behavior.

In order to construct the dependent variable for our regression analysis, we define the binary variable $C P R_{i, t}$ for $t \in\{2,3\}$, where $C P R_{i, t}=1$, [0] if individual $i$ 's response to the news released in period $t$ is [not] correct. The dependent variable is defined as the total number of correct responses to news of a given subject $i$ in periods 2 and 3: $\mathrm{CPR}_{i, 2}+$ $\mathrm{CPR}_{i, 3} \in\{0,1,2\}$. In table 8 , we present the regression results of the following specification.

$$
\mathrm{CPR}_{i, 2}+\mathrm{CPR}_{i, 3}=\beta_{0}+\beta_{1} \times \operatorname{Treatment}(i)+\beta_{2} \times \operatorname{News} 2(i)+\beta_{3} \times \operatorname{News} 3(i)+\varepsilon(i)
$$

We introduce a dummy treatment variable as a regressor (that takes value of one if the subjects participated in the ambiguity session). The other regressors correspond to the variable News $s_{t}$ News $_{t}$ measures the change in the fundamental value of the asset in period $t$. That is, it measures the change in the expected value of dividend streams between period $t$ and $t-1$ after the release of the news at the end of period $t-1 . N e w s_{t}$ is positive (negative) when the news at the end of period $t-1$ is good (bad). In the case of inexperienced subjects we find that the dummy treatment variable is positive and significant in the regressions of the total number of subjects' correct responses in periods 2 and 3 (table 8, left column).

\begin{tabular}{|c|c|c|}
\hline \multicolumn{2}{|c|}{$\begin{array}{c}\text { Table 8: Poisson count estimates for inexperienced [experienced] traders } \\
\text { Dependent variables: correct trading responses in periods } 2 \text { and3 } \\
\left(\mathrm{CPR}_{i, 2}+\mathrm{CPR}_{i, 3}\right), \mathrm{n}=89[\mathrm{n}=78]\end{array}$} \\
\hline $\begin{array}{c}\text { Coefficients } \\
\text { (P-values) }\end{array}$ & Inexperienced & Experienced \\
\hline \hline Intercept & -0.09 & $0.75^{* *}$ \\
\hline Treatment & $0.64^{* *}$ & -0.35 \\
\hline News in period 2 & 0.26 & -0.176 \\
\hline News in period 3 & 0.09 & 0.06 \\
\hline \hline R squared & 0.44 & 0.22 \\
\hline
\end{tabular}




\section{III.2.2. Analysis of the magnitude of price changes}

We now test Hypothesis 3ii) and assess whether changes in contract prices are over-, or under, reaction to news. Our previous analysis on price change consistency and correct trading responses does not inform us about the magnitude of price changes. As a result, we complement the analysis by defining the concepts of over- and under-reaction to news as follows.

Definition 4: (Contract price changes classification) For $t \in\{2,3\}$, a change in average contract prices between periods $t$ and $t-l$ is classified as under-reaction [over-reaction] if:

i) It is consistent and $P_{t}-P_{t-1}<N e w s_{t}\left[P_{t}-P_{t-1}>N e w s_{t}\right]$ in case of good news; or

ii) It is consistent and $P_{t}-P_{t-1}>N e w s_{t}\left[P_{t}-P_{t-1}<N e w s_{t}\right]$ in case of bad news.

The classification of price over-, under-, reaction and consistency is reported in table 9. For each treatment, we aggregate price under- and over-reaction for periods 2 and 3. A first look at the table suggests that the proportion of price changes characterized as overand under-reactions to news is similar across treatments. Using Definition 5, we test this conjecture (Hypothesis 3ii).

\begin{tabular}{|c|c|c|c|}
\hline \multicolumn{4}{|c|}{ Table 9: Classification of contract price changes for inexperienced [experienced] traders by treatments ${ }^{17}$} \\
\hline & Over-reaction & Under-reaction & Inconsistent \\
\hline Baseline & $3 / 8[5 / 9]$ & $3 / 8[3 / 9]$ & $2 / 8[1 / 9]$ \\
\hline Ambiguity & $3 / 9[3 / 9]$ & $3 / 9[3 / 9]$ & $3 / 9[3 / 9]$ \\
\hline \hline $\begin{array}{c}\text { Aggregate (Baseline \& } \\
\text { Ambiguity) }\end{array}$ & $6 / 17[8 / 18]$ & $6 / 17[6 / 18]$ & $5 / 17[4 / 18]$ \\
\hline
\end{tabular}

Definition 5: (Over- and under-reaction in asset markets) An asset market is characterized by under-reaction [over-reaction] if the proportion of contract price changes

\footnotetext{
${ }^{17}$ We classify a total of 17 price changes ( 8 inexperienced sessions and 9 experienced sessions) for the baseline sessions and 18 (9 inexperienced sessions and 9 experienced sessions) price changes for the ambiguity sessions. Recall that over the 24 price changes in the baseline (ambiguity) sessions, 7 (6) of them could not be qualified as either consistent or inconsistent.
} 
classified as under-reaction [over-reaction] is significantly larger than the proportion of contract price changes classified as over-reaction [under-reaction].

\section{Result 6: (Over- and under-reaction to news)}

Neither the baseline, nor the ambiguity treatments are characterized by a significantly larger proportion of contract price changes that are classified as either over- or underreaction to news. This result holds regardless of subject experience.

Support: In table B.4 (appendix) we provide a summary of the tests for the presence of over- or under-reaction in ambiguity and baseline treatments. This finding is in line with Fama's critique (1998) that downplays the robustness of studies showing under- or overreaction of contract prices to news. We confirm Hypothesis 3ii) that states that overreaction in contract prices is not more likely than under-reaction in contract prices. This is true regardless of whether the underlying asset value is ambiguous or not. Result 6 is in line with Results 4 and 5 where we show that price changes are highly consistent to news regardless of subject experience and the ambiguity of the environment.

Using regression analysis we confirm Result 6 where we assess the impact of news on average contract prices in periods 2 and 3 . The dependent variable is the average contract price in periods 2 and 3 in a given experimental session. We control for the level of mispricing in the previous period. We define it as the difference between average contract prices in period $t$ and the fundamental value of the asset in that period. The fundamental value of the asset in period $t$ is computed as the expected dividend stream given the information released up to that period.

Controlling for asset mispricing in previous periods is important in order to measure contract prices reaction to the release of news in a given period. For example, an increase in contract prices in the second period of trading may be either due to the release of good news or to a positive trend in contract prices (e.g. prices were much lower than the fundamental value in the first period in the baseline treatment). We also introduce a treatment dummy variable that takes a value of one if the session corresponds to the 
ambiguity treatment. ${ }^{18}$ In addition, we incorporate an interaction variable between the treatment dummy and the news variable (Treatment $\times$ News). This variable measures whether reaction to news is significantly different across treatments. Finally, we introduce a dummy variable that takes value of one for experienced subjects. ${ }^{19}$

We estimated the following regressions.

$$
P_{2}(i)=\beta 0+\beta 1 \times \operatorname{News} 2(i)+\beta_{2} \times \operatorname{Treatment}(i)+\beta 3 \times[\operatorname{Treatment}(i) \times \operatorname{News} 2(i)]+
$$
$\beta 4 \times$ Mispricing in period $1(i)+\beta 5 \times$ experience $(i)+\varepsilon(\mathrm{i})$$$
P_{3}(\mathrm{i})=\beta 0+\beta 1 \times \operatorname{News} 3(i)+\beta_{2} \times \operatorname{News} 2(i)+\beta 3 \times \operatorname{Treatment}(i)+
$$$$
\beta 4 \times[\text { Treatment }(i) \times \operatorname{News} 3(i)]+\beta 5 \times \text { Mispricing in period } 2(i)+\beta 6 \times \operatorname{experience}(i)+
$$ $\varepsilon(i)$

\begin{tabular}{|c|c|c|}
\hline \multicolumn{2}{|c|}{ Table 10: OLS estimates of the regression of average contract prices on news } \\
\hline Coefficients (P-values) & $P_{2}$ & $P_{3}$ \\
\hline \hline Intercept & $152.18^{* * *}$ & $157.02^{* * *}$ \\
\hline News,2 & $0.90^{* * * *}$ & $1.07^{* * *}$ \\
\hline News,3 & - & $1.11^{* * *}$ \\
\hline Treatment & 9.42 & -9.77 \\
\hline Treatment×News,2 & -0.36 & - \\
\hline Treatment×News,3 & - & $-1.09^{* *}$ \\
\hline Mispricing in previous period & 0.08 & $1.06^{* * *}$ \\
\hline Experience & -9.92 & -1.99 \\
\hline \hline R squared & 0.54 & 0.79 \\
\hline
\end{tabular}

In both the regressions the coefficient for news is highly significant. This confirms that contract prices significantly react to news. Using a Wald test we cannot reject that the $\beta_{1}$ coefficient (associated with current period news) is equal to one. For the regression of contract prices in period 2 and 3, the p-values are 0.690 and 0.730 ,

\footnotetext{
${ }^{18}$ This variable allows us to control for the fact that prices may be systematically different across treatments (as seen in the case of inexperienced traders in Result 1).

${ }^{19}$ In contrast with individual trading behavior regressions (table 8) we do not consider separate regressions for experienced and inexperienced sessions. The rationale is that we have much less data available in our aggregate analysis compared to the analysis of individual data.
} 
respectively. This means that an increase (decrease) of one monetary unit in the fundamental value of the asset is followed by an increase (decrease) of the same magnitude in average asset prices in the period in which the news have been released. This result confirms the absence of under- or over-reaction as established previously using non-parametric tests. The only effect associated with ambiguity is due to the significance of the interaction coefficient between the treatment dummy and news in period 3. This coefficient tells us that in the ambiguity treatment the reaction to news in period 3 is significantly more negative. This result is consistent with Epstein and Schneider (2008) and Leippold, Trojani and Vanini (2007) that show that contract prices react more strongly to bad news than to good news in a context of ambiguous information. ${ }^{20}$ Veronesi (1999) also shows that in the presence of uncertainty asset prices tend to overreact to bad news in good times.

\section{Conclusion}

Research in behavioral finance makes specific predictions about the existence of price under- and over-reaction (e.g. Daniel, Hirshleifer and Subrahmanyam (1998) and Barberis, Shleifer and Vishny (1998)). In this paper, we use a standard double auction experimental asset market to study the reaction of contract prices to public news. We find that prices do not over or under-react to news and consistently move in the direction of the fundamental value. Interestingly, the absence of under-or over-reaction to news is robust to the introduction of ambiguity in the fundamental value of the asset. Specifically, we control for the presence of ambiguity in our experimental asset markets by designing two distinct environments in which the distribution of dividends is either known (risky asset) or unknown (ambiguous asset) to the traders.

We compare market variables in the risky and ambiguous environments and find no support for the existence of an ambiguity premium. Contrary to expectations, prices in the ambiguity treatment are actually higher than the baseline, and are closer to the

\footnotetext{
${ }^{20}$ Period 3 results should be interpreted with care since our aggregate analysis of price reaction to news is based on only 11 sessions ( 5 sessions with inexperienced subjects and 6 sessions with experienced subjects). This is due to the fact that we drop the observations corresponding to the release of neutral news in period 2 .
} 
fundamental value. This difference is only significant for inexperienced subjects. In the absence of experience ambiguity tends to generate greater levels of volatility in contract prices compared to the risky environment. However, any difference in contract prices or volatility disappears with experience. This suggests that any anomaly in trading behavior that would follow from the presence of ambiguity is only short-lived.

The advantage of our experimental methodology is that we can precisely study the effect of ambiguity in a controlled environment. Such an exercise would be practically impossible due to the various confounding factors one faces in the real market situations. Our experiments point towards several future directions of research. For example, it would be interesting to analyze asset markets with different forms of ambiguity. A possibility could be to introduce ambiguity both in the fundamental value of the asset as well as in the information. Another possibility would be to consider not only public but, also private, information (Daniel, Hirshleifer and Subrahmanyam (1998)) to further study the effect of ambiguity on price reaction to news.

\section{$\underline{\text { V. References }}$}

Barberis, N., A. Shleifer, R.Vishny. 1998. A model of investor sentiment. Journal of Financial Economics 49: 307-343.

Bossaerts, P., P. Ghirardato, S. Guarnaschelli, W. Zame. 2010. Ambiguity and asset markets: Theory and experiment. Review of Financial Studies 23: 1325-1359.

Camerer, C., M. Weber. 1992. Recent developments in modeling preferences: Uncertainty and ambiguity. Journal of Risk and Uncertainty 5: 325-370.

Campbell, J.Y., J. Cochrane. 1999. By force of habit: a consumption-based explanation of aggregate stock market behavior. Journal of Political Economy 107: 205-251.

Caskey, J. 2009. Information in equity markets with ambiguity-averse investors. Review of Financial Studies 22: 3595-3627.

Chow, C., and R. Sarin.2002. Known, unknown and unknowable uncertainties. Theory and Decision 52: 127-138.

Cohen, M., J. Y. Jaffray, T. Said. 1985. Individual behavior under risk and under uncertainty : an experimental study. Theory and Decision 18,203-228. 
Cohen, M., J. M. Tallon, J.C. Vergnaud. 2009. An experimental investigation of imprecision attitude and its relation with risk attitude and impatience. mimeo Université Paris I.

Curley, S., F. Yates. 1985. The center and range of the probabilityinterval as factors affecting ambiguity preferences. Organizational Behavior and Human Decision Processes 36: 272-287.

Daniel, K., D. Hirshleifer, A. Subrahmanyam. 1998. A theory of overconfidence, selfattribution, and security market under- and over-reactions. Journal of Finance 53: 1839-1886.

Dickhaut, J., N. Wilcox. 2009. The economic science institute risk attitude battery: An introduction and initial user's guide. Mimeo. ChapmanUniversity.

DeBondt, W., R. Thaler.1985. Does the stock market overreact? Journal of Finance 40: 793-805.

Dow, J., S. da Costa Werlang. 1992.Uncertainty aversion, risk aversion, and the optimal choice of portfolio. Econometrica 60: 197-204.

Du, N., and D. Budescu, 2005.The Effects of imprecise probabilities and outcomes in evaluating investment options. Management Science 51: 1791-1803.

Dufwenberg, M., Lindqvist, T., E. Moore. 2005. Bubbles and experience: an experiment. American Economic Review 95: 1731-1737.

Ellsberg, D. 1961. Risk, ambiguity, and the Savage axioms. Quarterly Journal of Economics 75 643-669.

Epstein, L., T. Wang. 1994. Intertemporal asset pricing under Knightian uncertainty. Econometrica 62: 283-322.

Epstein, L., M. Schneider. 2008. Ambiguity, information quality and asset prices. Journal of Finance 63: 197-228.

Fama, E. 1998. Market efficiency, long-term returns, and behavioural finance. Journal of Financial Economics 49: 283-306.

Fox, C., A. Tversky. 1995. Ambiguity aversion and comparative ignorance. Quarterly Journal of Economics 110: 585-603. 
Frazzini, A. 2006. The disposition effect and under-reaction to news. Journal of Finance 62: 2017-2046.

Jegadeesh, N., S.Titman. 1993. Returns to buying winners and selling losers: Implications for stock market efficiency. Journal of Finance 48: 65-91.

Ju, N., J. Miao. 2009. Ambiguity, learning, and asset returns. AFA 2009 San Francisco Meetings Paper

Lei, V., Noussair, C. C. Plot. 2001. Nonspeculative bubbles in experimental asset markets: Lack of common knowledge of rationality vs. actual irrationality. Econometrica 69: 831-859.

Leippold, M., F. Trojani,P. Vanini. 2008. Learning and asset prices under ambiguous information. Review of Financial Studies 21: 2565-2597.

Lin, S.,S. Rassenti. 2008. Are under- and over-reaction the Same Matter? A price inertia based account. ChapmanUniversity Economic Science Institute Working Paper Series $05 / 08$.

Mukerji, S., J. M.Tallon. 2001.Ambiguity aversion and incompleteness of financial markets. Review of Economic Studies 68: 883-904.

Myung, N. 2009.Ambiguity aversion in asset market: Experimental study of home bias. Mimeo, California Institute of Technology.

Palan, S. 2009. Bubbles and crashes in experimental asset markets, lecture notes in Economics and Mathematical Systems. Springer 626.

Sarin, R., M. Weber. 1993. Effects of ambiguity in market experiments. Management Science 39: 602-615.

Shefrin, H. 2000. "Beyond greed and fear: Understanding behavioral finance and the psychology of investing" Financial Management Association Survey and Synthesis Series.Boston, MA: Harvard Business School Press.

Shiller, R. 2000.Irrational Exuberance. Princeton University Press.

Smith, V., Suchanek, G., A. Williams. 1988. Bubbles, crashes and endogenous expectations in experimental spot asset markets. Econometrica 56: 1119-1151. 
Smith, K, Dickhaut,J., McCabe, K., J. Pardo. 2002. Neuronal substrates for choice under ambiguity, risk, gains, and losses. Management Science 48: 711-718.

Ui, T. 2010. The ambiguity premium vs. the risk premium under limited market participation. Review of Finance 14: 1-31.

Veronesi, P. 1999. Stock Market Overreaction to Bad News in Good Times: A Rational Expectations Equilibrium Model. Review of Financial Studies12: 975-1007.

Yates, F., L. Zukowski.1976. Characterization of ambiguity in decision making. Behavioral Science 21: 19-25.

\section{Appendices}

\section{Appendix A: Instructions}

$\underline{\text { I. Instructions for the baseline treatment (full set of instructions with screenshots) }}$ 


\section{INSTRUCTIONS}

This is an experiment in market decision making. You will be paid in cash for your participation at the end of the experiment. Different participants may earn different amounts. What you earn depends on your decisions and the decisions of others.

The experiment will take place through computer terminals at which you are seated. If you have any questions during the instruction round, raise your hand and a monitor will come by to answer your question. If any difficulties arise after the experiment has begun, raise your hand, and someone will assist you.

Click "Next" to continue Next 


\section{INSTRUCTIONS}

In this experiment you will be able to buy and sell a commodity, called Shares, from one another.

At the start of the experiment, every participant will be given some Cash and Shares.

Each share will pay a dividend when the last period of trading ends. The amount you make is equal to the dividends you earn and the remaining cash you have after making buys and sells in the market.

The amount of the dividend is unknown but you will receive information during the experiment that will assist you in narrowing what the dividend will be at the end of trading.

Click "Next" to continue Back Next 


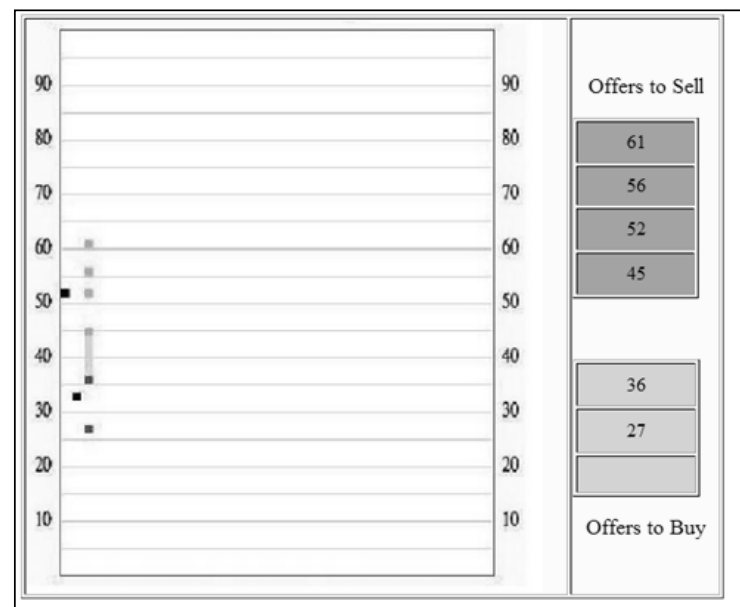

\section{INSTRUCTIONS}

During every round, Traders can buy or sell shares from one another by making offers to buy or to sell.

Every time someone makes an offer to buy a share, a GREEN dot will appear on the graph to the left. Every time someone makes an offer to sell, an ORANGE dot will appear on the graph to the left. The offers to buy will be listed in ascending order in appear on the graph to the left. The offers to buy will be listed in ascending order
GREEN, while the offers to sell will be listed in descending order in ORANGE.

Once a trade is actually made, it will be shown as a BLACK dot in the graph. Offers are also listed on the Market Book to the right of the graph.

Back Next

Your Holdings
\begin{tabular}{|l|l|}
\hline Cash & 150 \\
\hline Shares & 3 \\
\hline
\end{tabular}

The dividend will be selected from the the numbers $\{50,100,150\}$ OR $\{100,200,300\}$

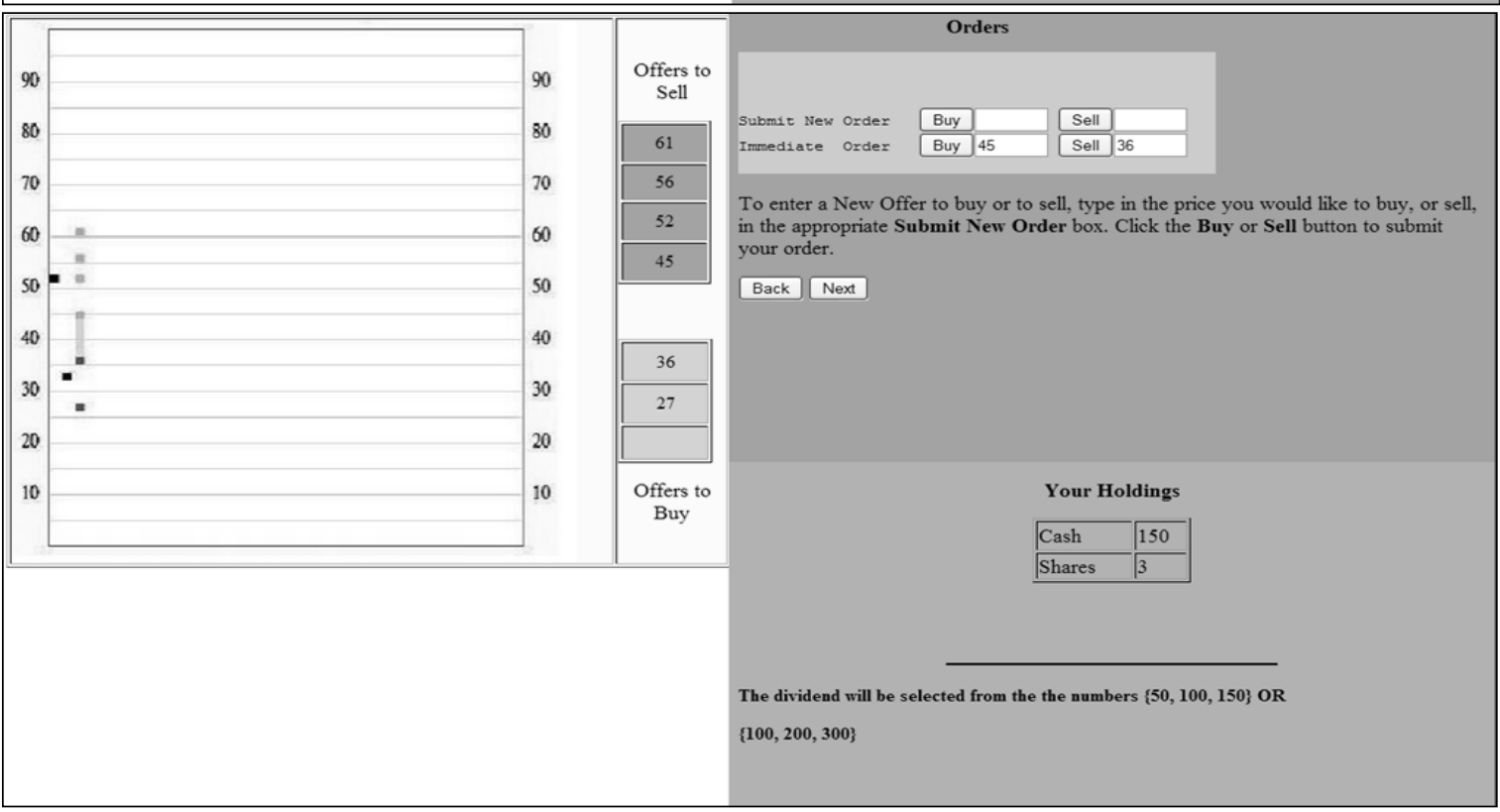



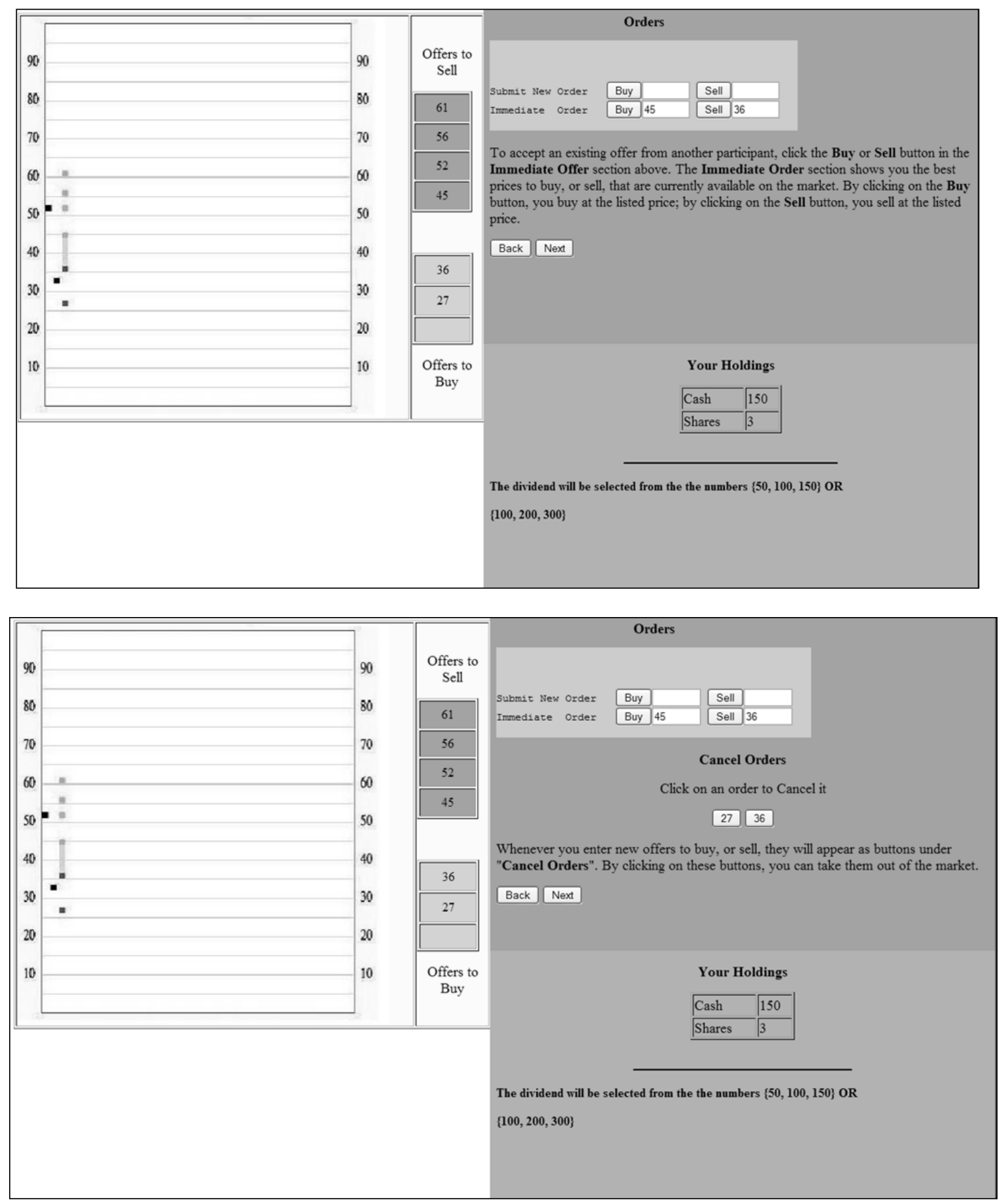


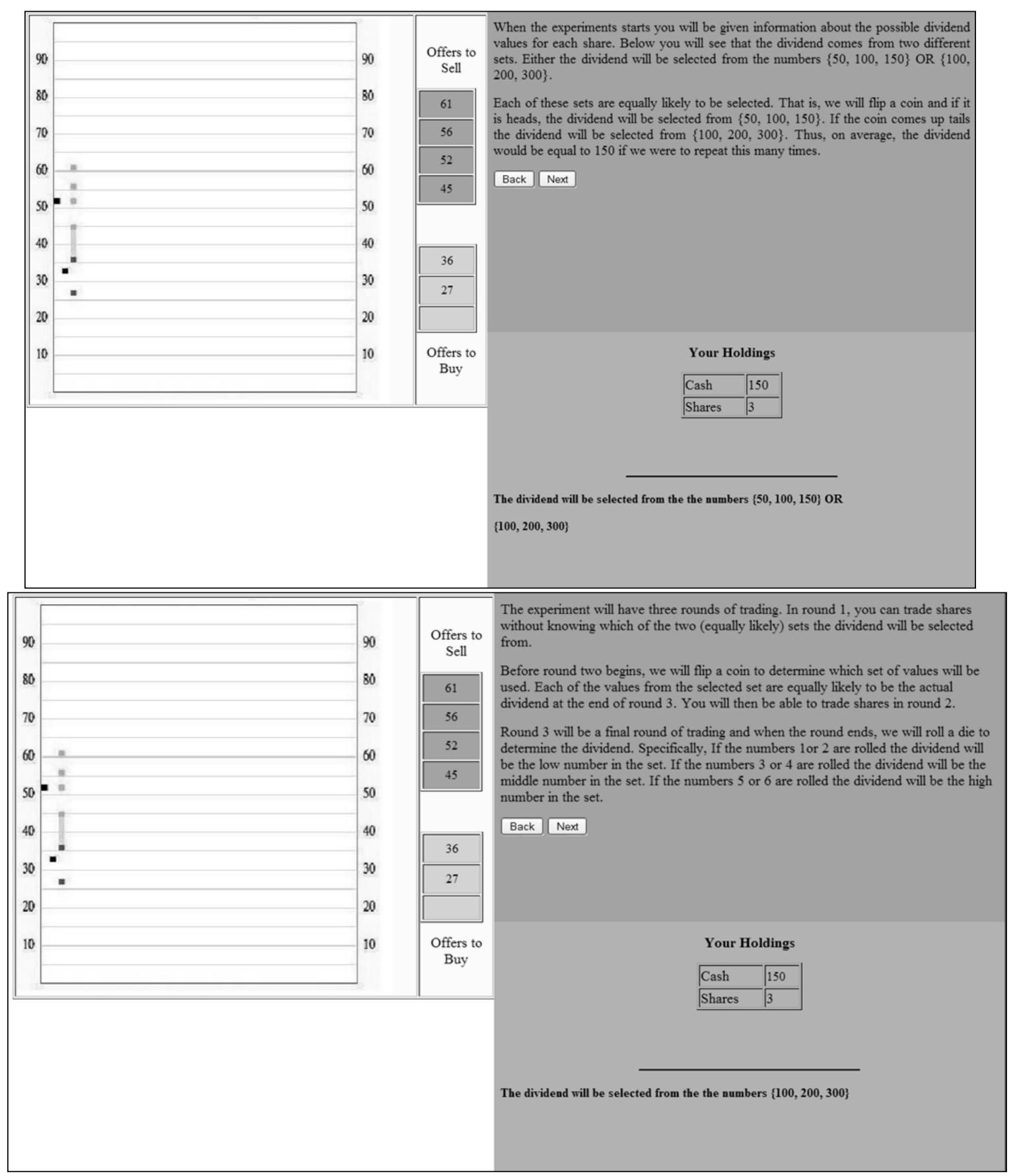



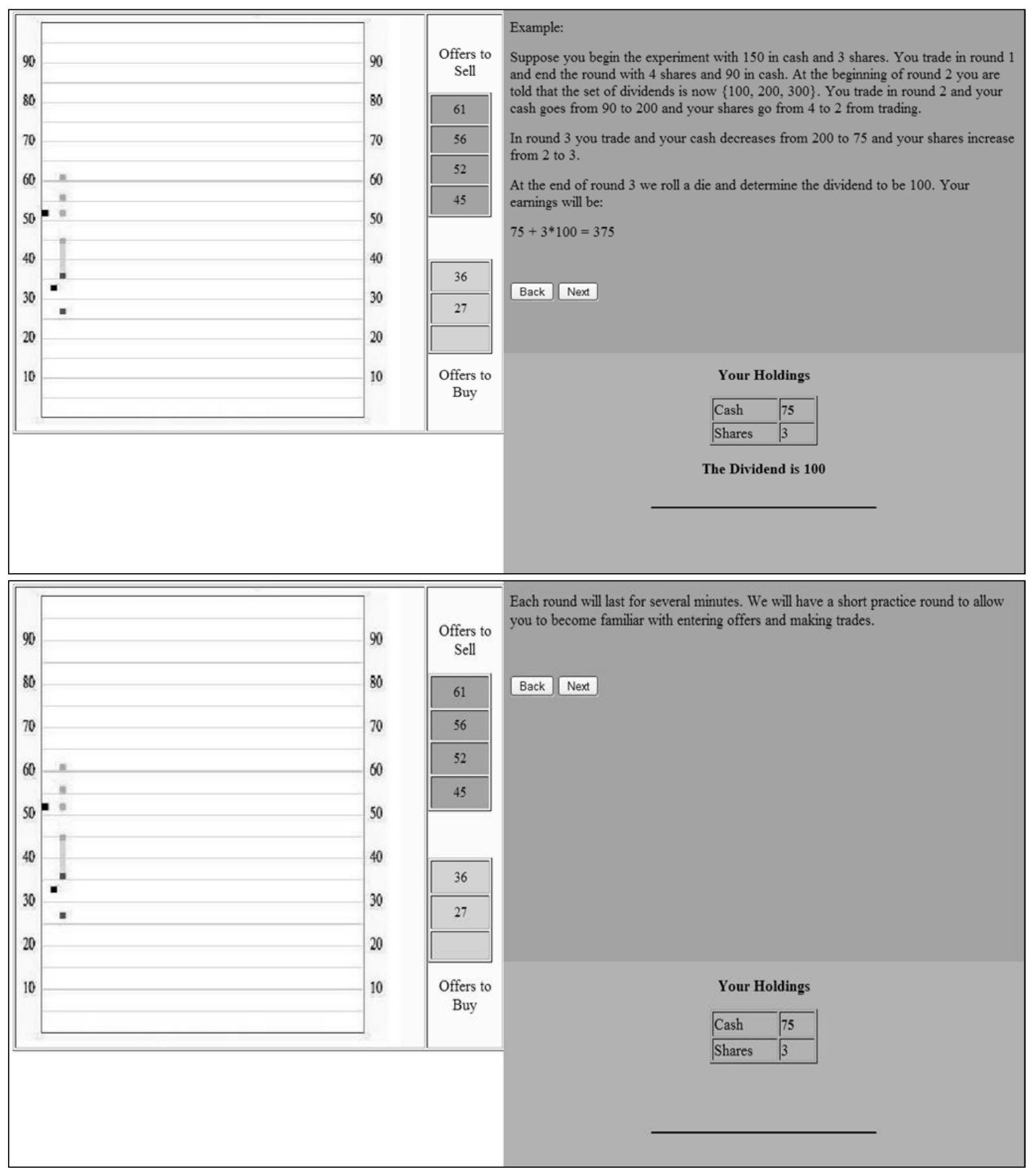


\section{Summary}

1. You will be given an initial amount of Cash and Shares.

2. Every share generates a dividend from the set $\{50,100,150\}$ or $\{100,200$, $300\}$ both of which are equally likely to be selected. We will flip a coin, if the toss is heads the set will be $\{50,100,150\}$, if it is tails the set will be $\{100,200$, $300\}$.

3. You can submit offers to BUY shares and offers to SELL shares.

4. You make trades by buying at the current lowest offer to sell or selling at the current highest offer to buy.

5. The experiment will have three trading rounds. At the beginning of round 2 we will announce which of the sets was selected from the coin flip.

6. At the end of round 3 , if the numbers 1 or 2 are rolled the dividend will be the low number in the set. If the numbers 3 or 4 are rolled the dividend will be the middle number in the set. If the numbers 5 or 6 are rolled the dividend will be the high number in the set.

8. Your earnings will be equal to the ending cash at round 3 plus your shares at the end of round 3 times the dividend.

To go onto the review quiz, please click Next. Next 
II. Instructions for the ambiguity treatment (full set of instructions with screenshots)
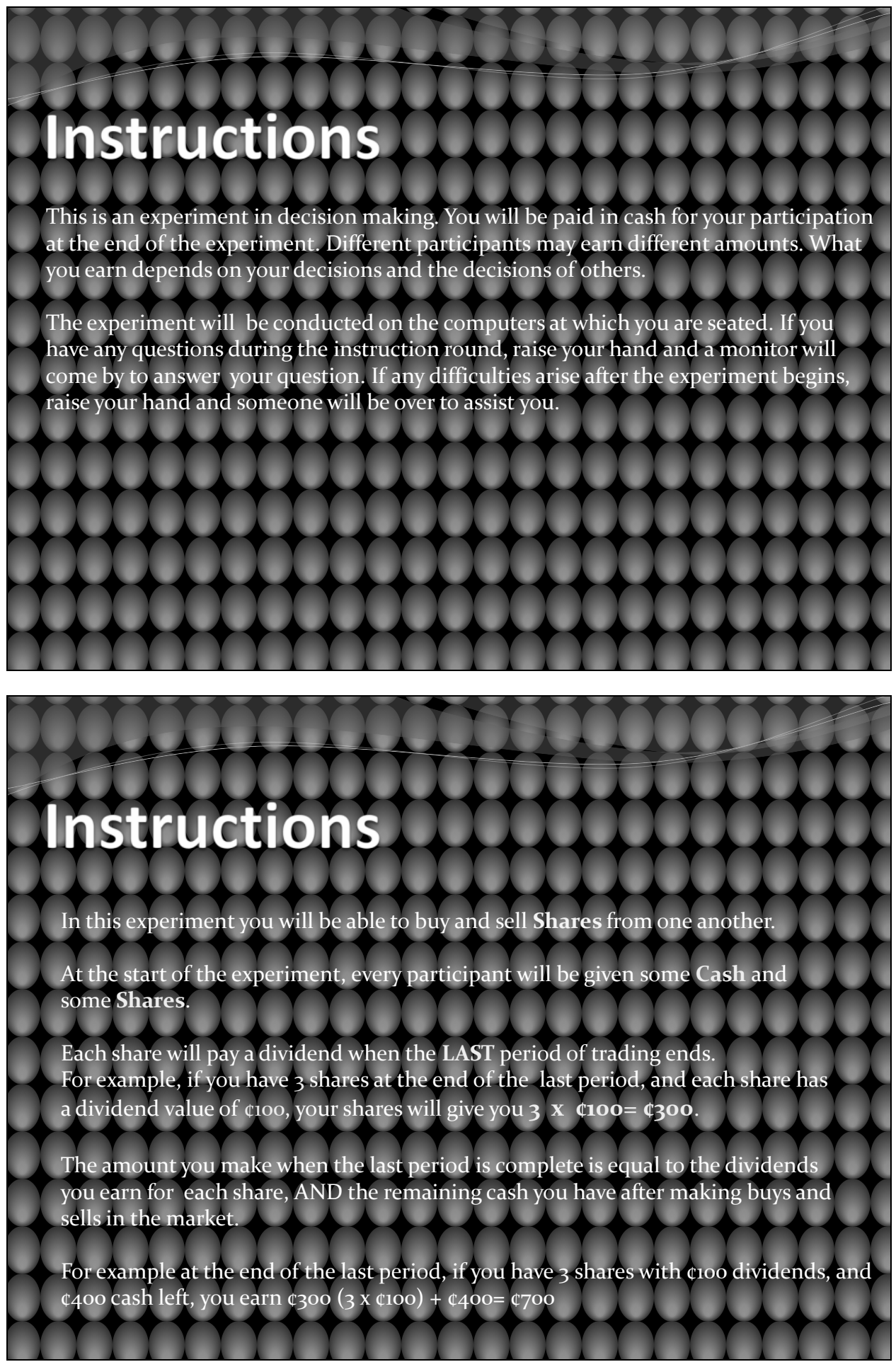

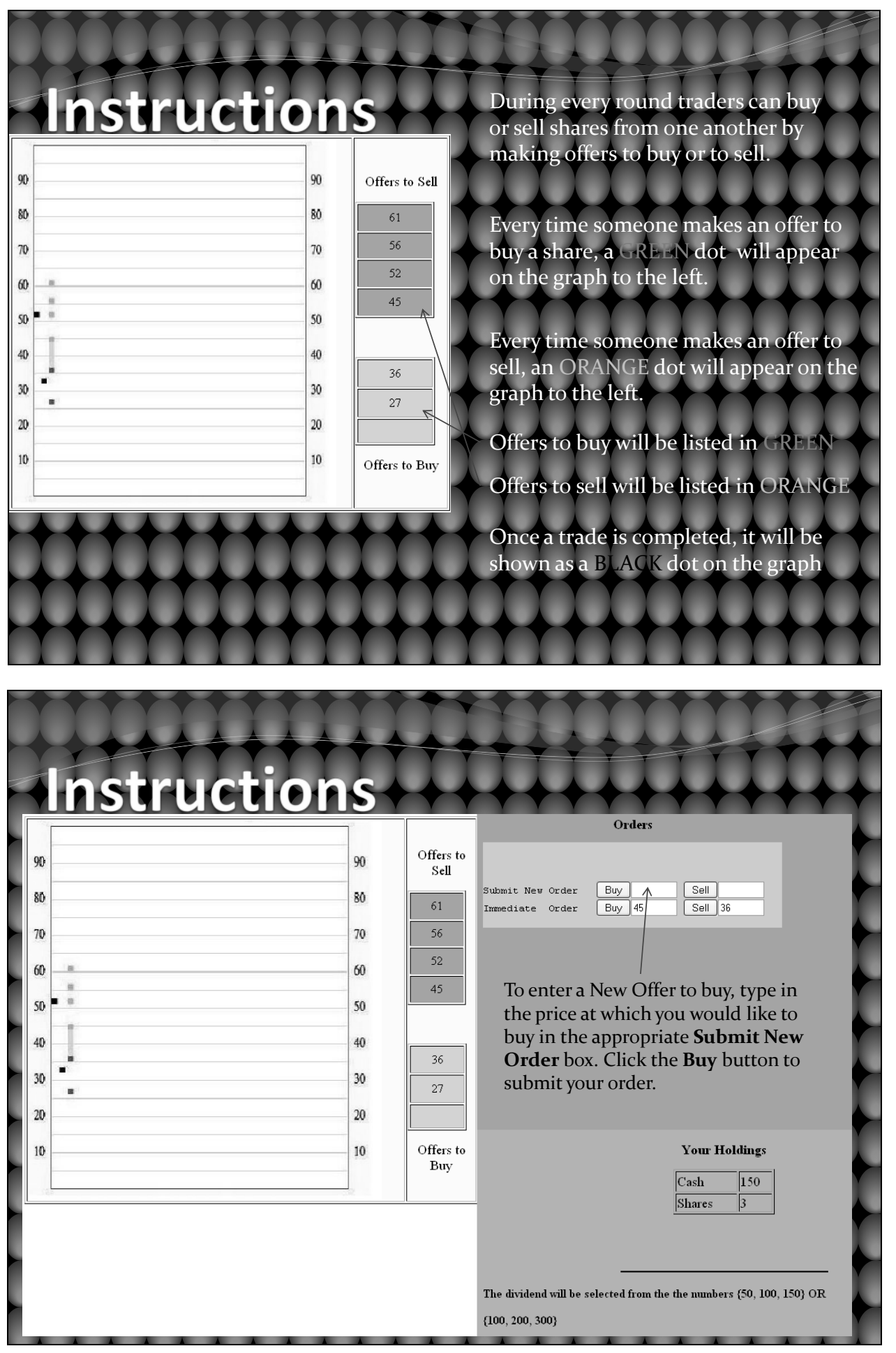

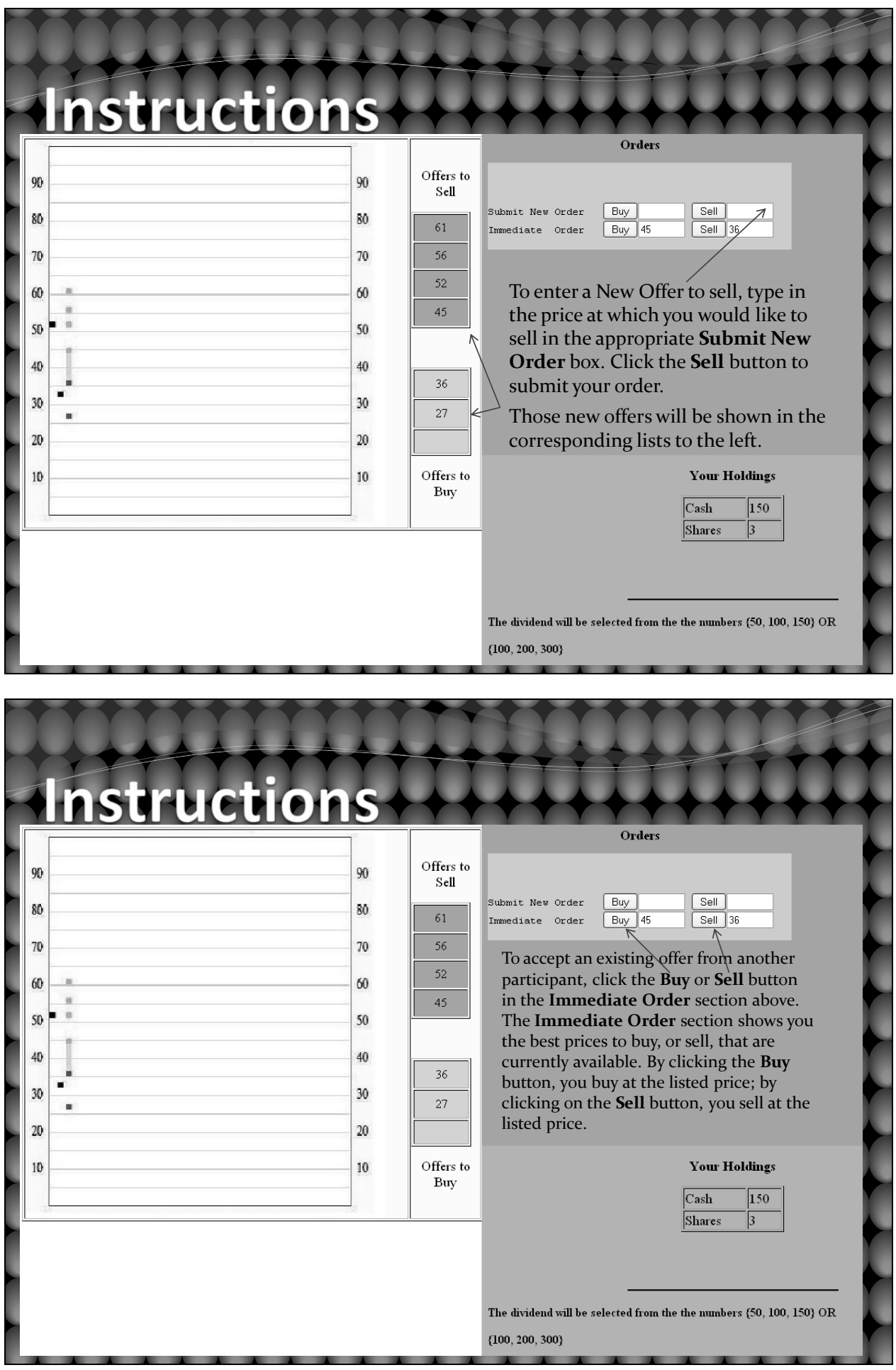

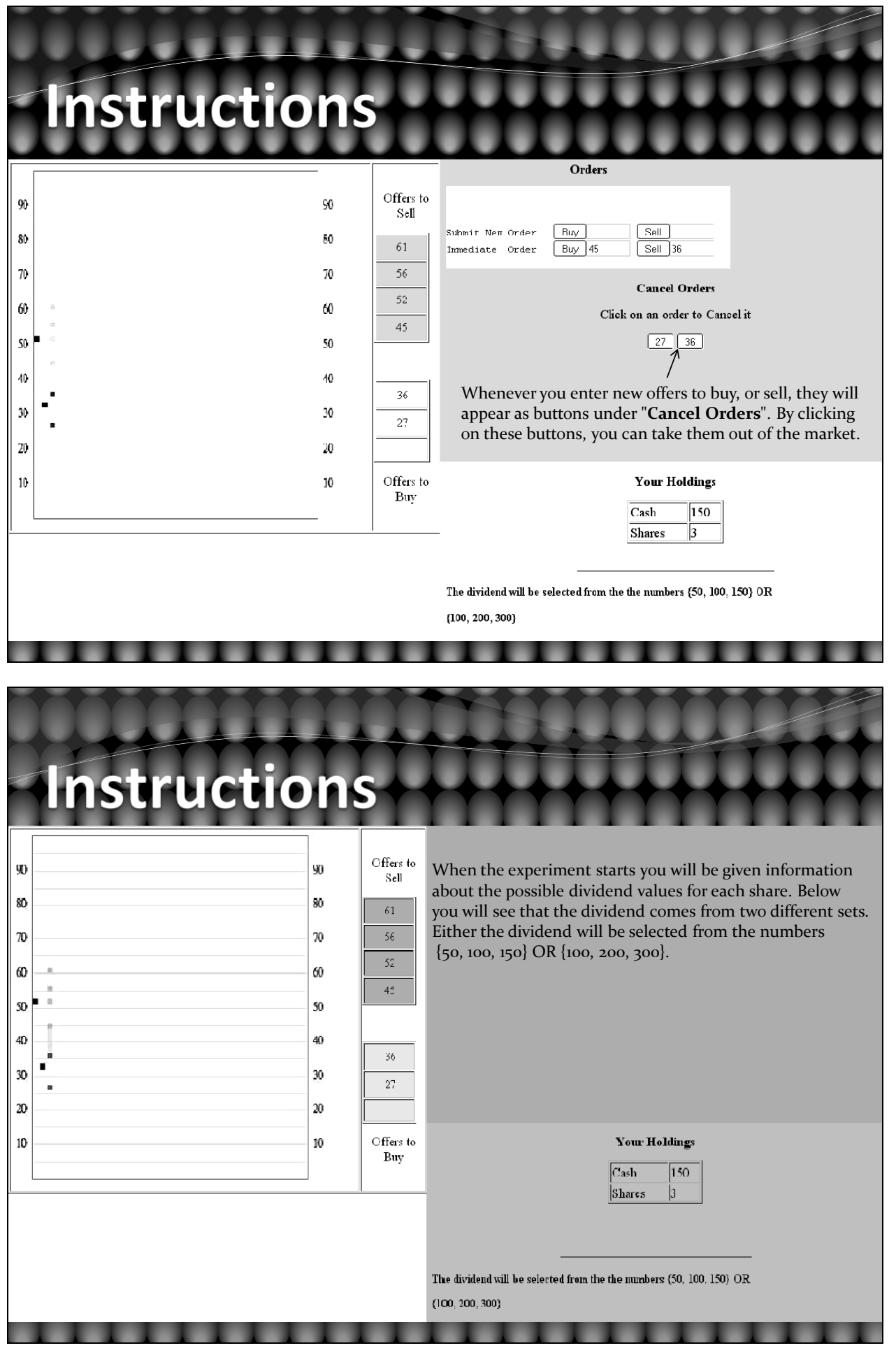

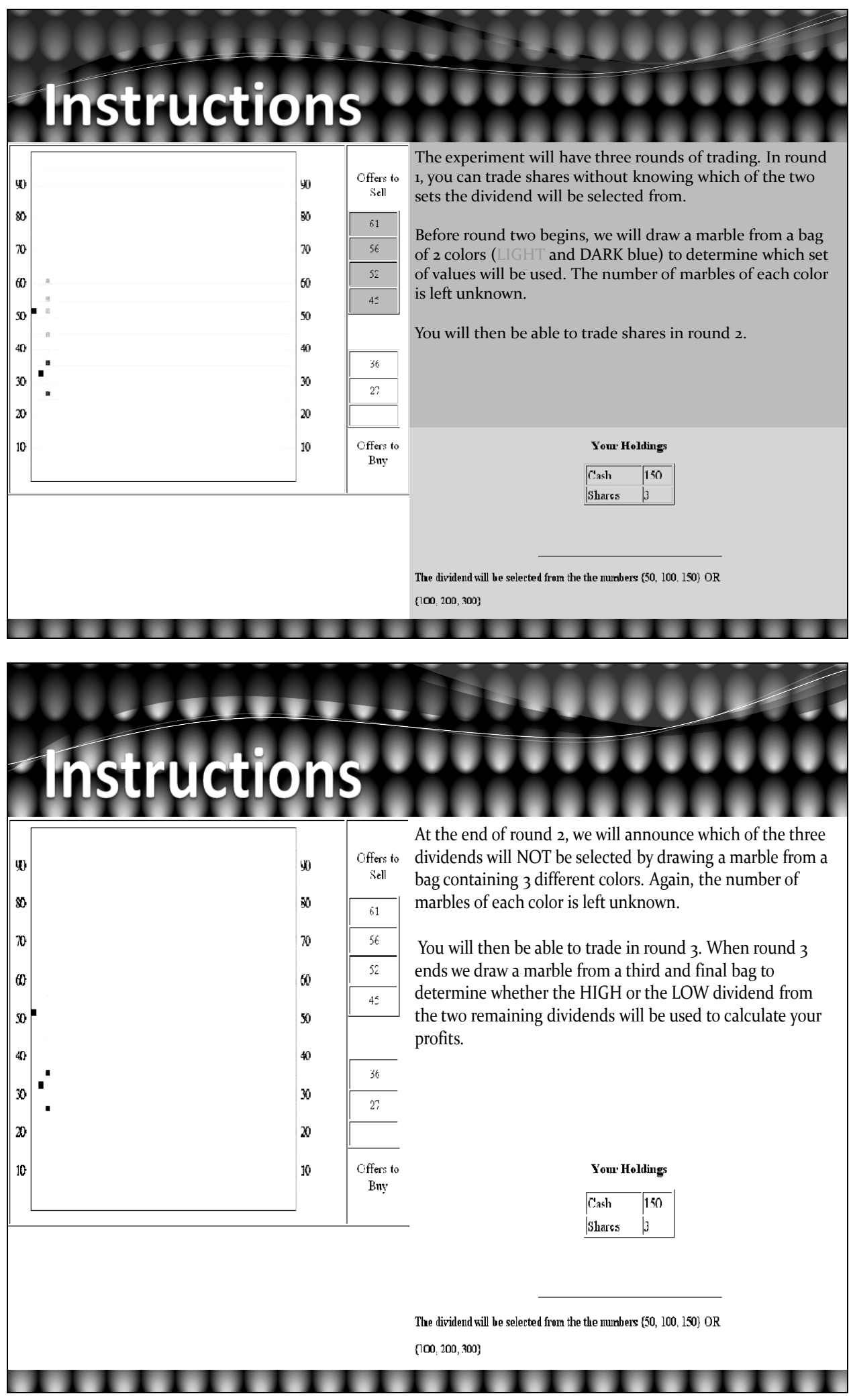

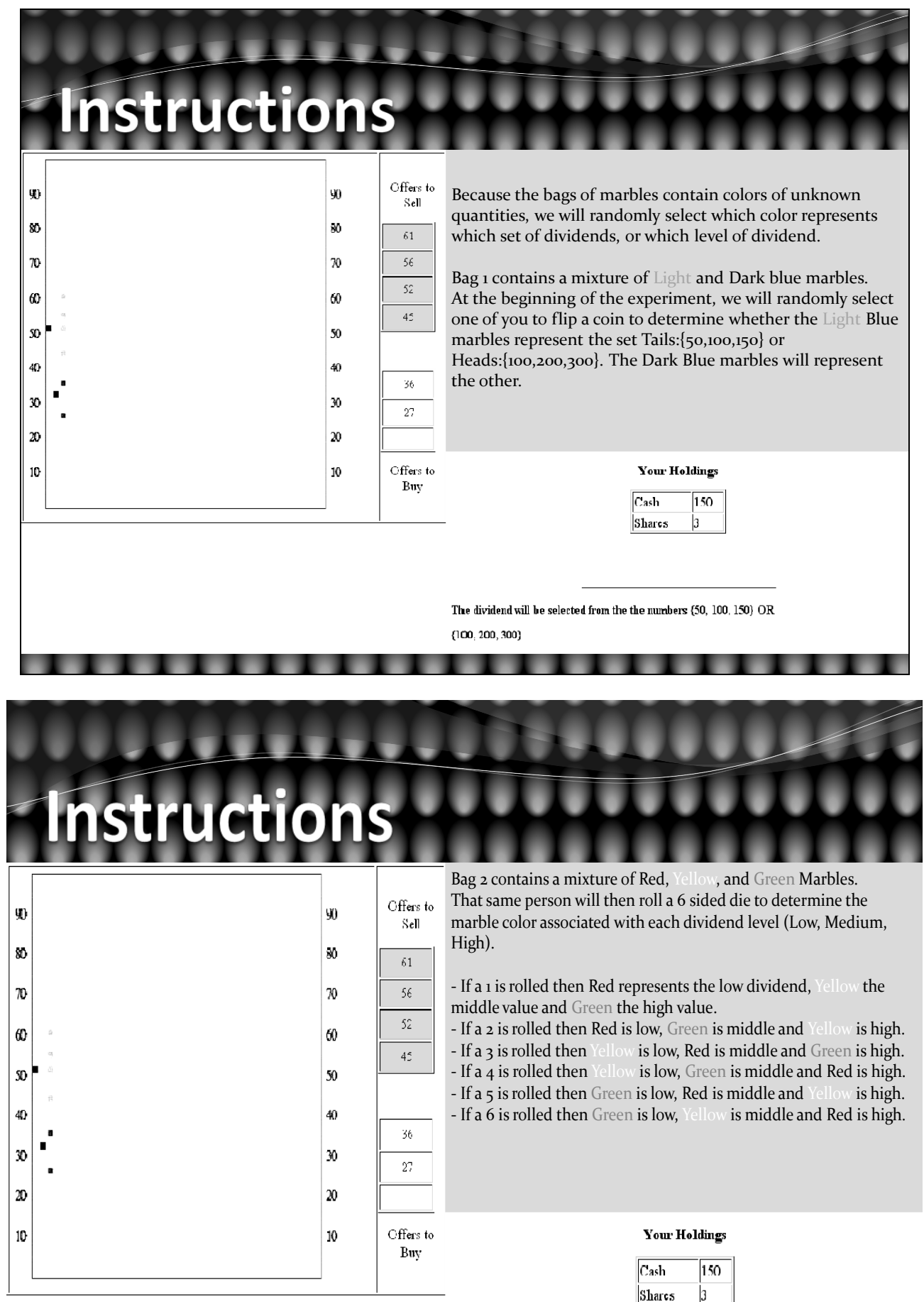

Bag 2 contains a mixture of Red, Yellow, and Green Marbles.

That same person will then roll a 6 sided die to determine the

Sell marble color associated with each dividend level (Low, Medium, High).

- If a 1 is rolled then Red represents the low dividend, Yellow the middle value and Green the high value.

- If a 2 is rolled then Red is low, Green is middle and Yellow is high. - If a 3 is rolled then Yellow is low, Red is middle and Green is high. - If a 4 is rolled then Yellow is low, Green is middle and Red is high. - If a 5 is rolled then Green is low, Red is middle and Yellow is high. - If a 6 is rolled then Green is low, Yellowis middle and Red is high.

The dividend will he selected from the the numbers $\{50,100,150\} \mathrm{OR}$

$\{100,200,300\}$

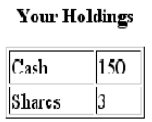



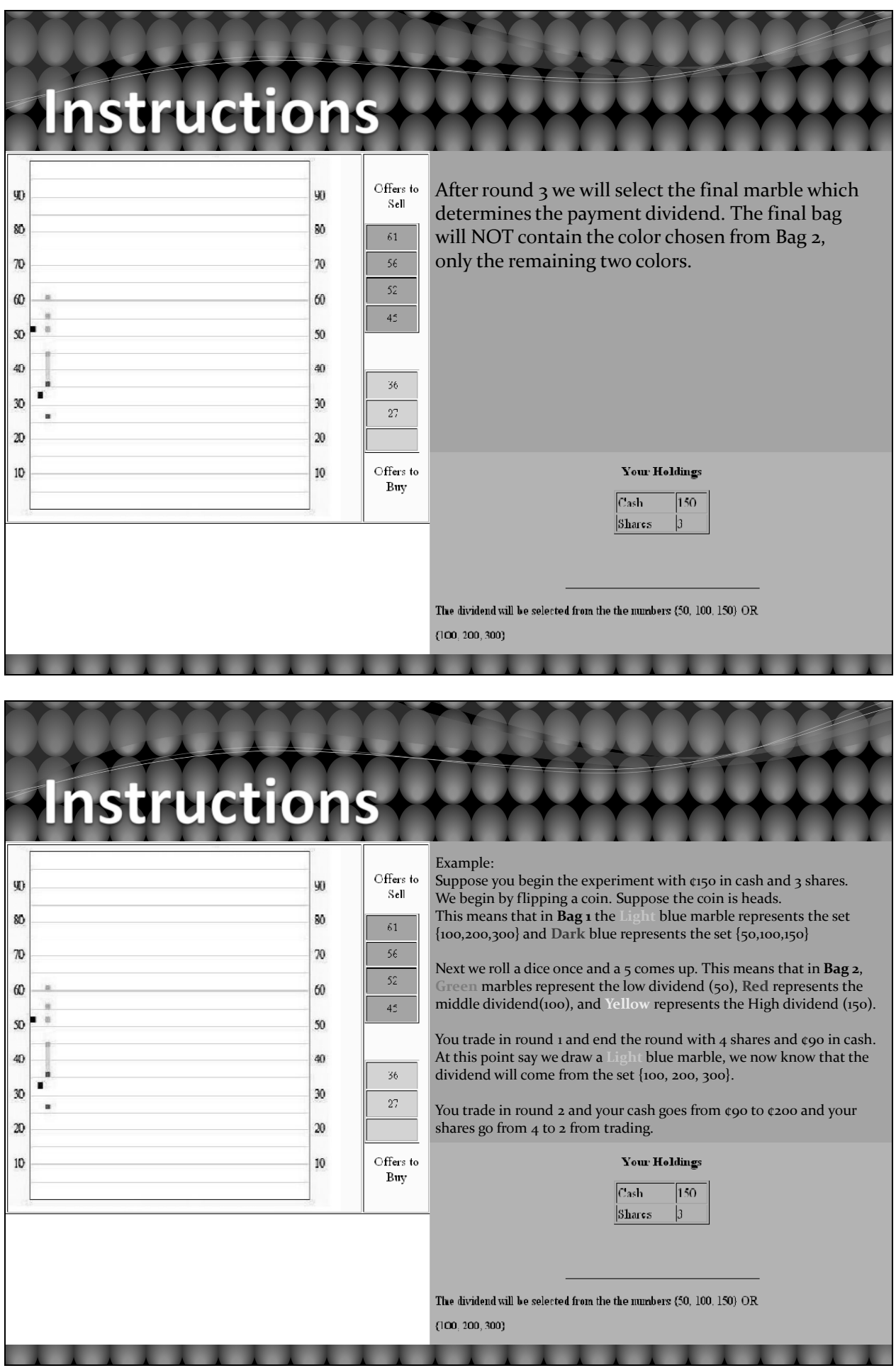

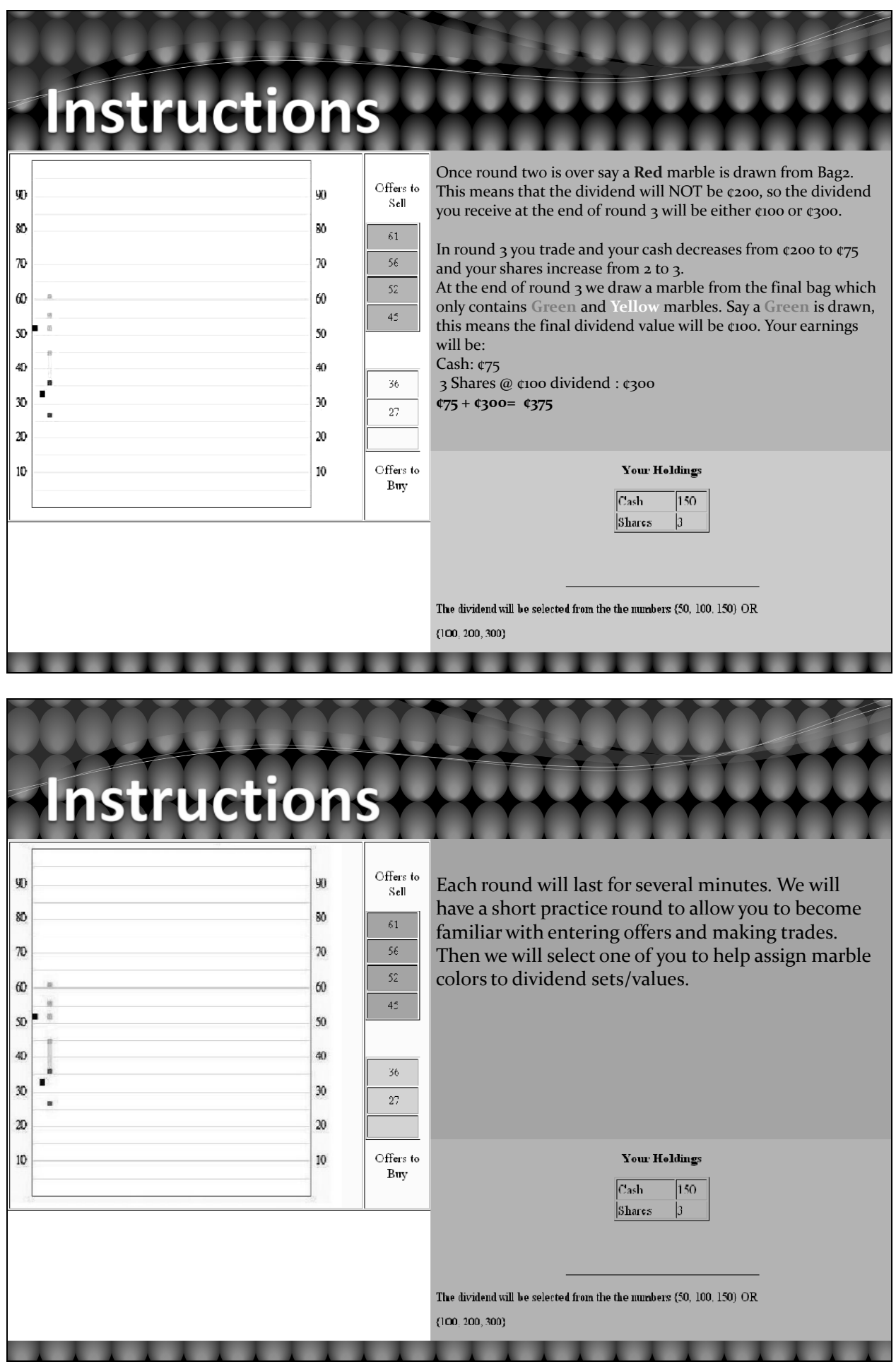

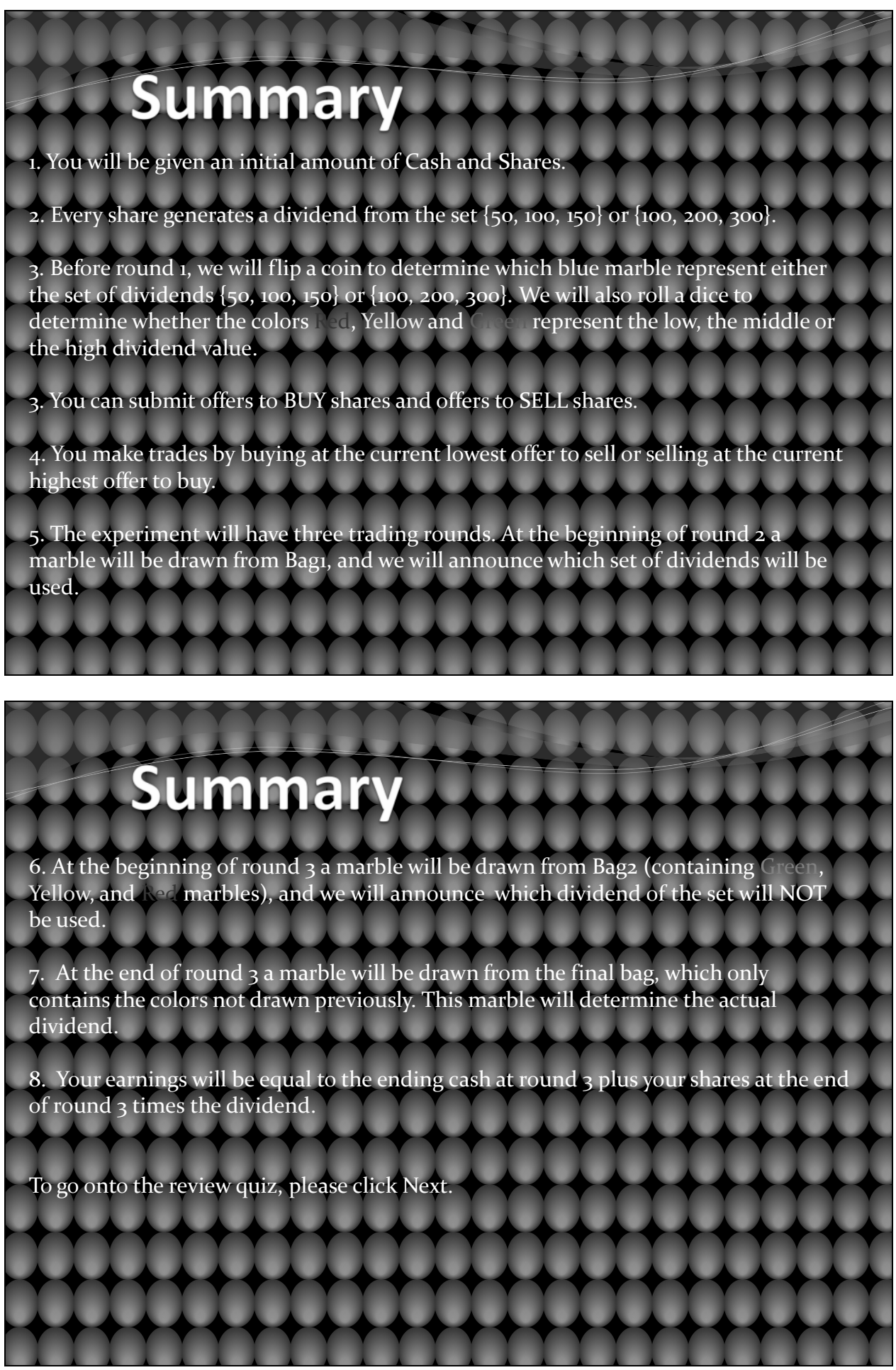


\section{$\underline{\text { Appendix B }}$}

\section{$\underline{\text { I. Mispricing analysis }}$}

Mispricing is defined as the difference between average price and fundamental value (the expected value of the future stream of dividends). Average mispricing in the baseline treatment is -31.3 . Given that the fundamental value of the asset in the baseline treatment is 150 in period 1 , this suggests that subjects trade below $\mathrm{t}$ he fundamental value. The results for the ambiguity treatment go in the opposite direction. Subjects trade above the fundamental value in the presence of ambiguity. The magnitude of mispricing is 15.2 for the ambiguity treatment. The extent of the deviation from the fundamental value is nearly $50 \%$ less than the baseline treatment. Our results suggest that information cognition with less information differs among subjects relative to the baseline treatment where information is clearer. It may be the case that subjects pay more attention to the problem at hand under ambiguity. This may suggest better information cognition under ambiguity. This difference is, however, not maintained when subjects are experienced. This result suggests that experts are less affected by ambiguity.

We illustrate the patterns of average mispricing for sessions with inexperienced and experienced subjects in Figure B.1. One sees that the patterns of mispricing are significantly different between the ambiguity and the baseline treatment for inexperienced subjects. For experienced sessions both treatments are characterized by prices above fundamental value in the first session. With experience, an opposite reaction is found. 
Figure B.1:Average mispricing per period for the baseline and the ambiguity treatment with inexperienced (session 1) subjects and experienced subjects (session 2)

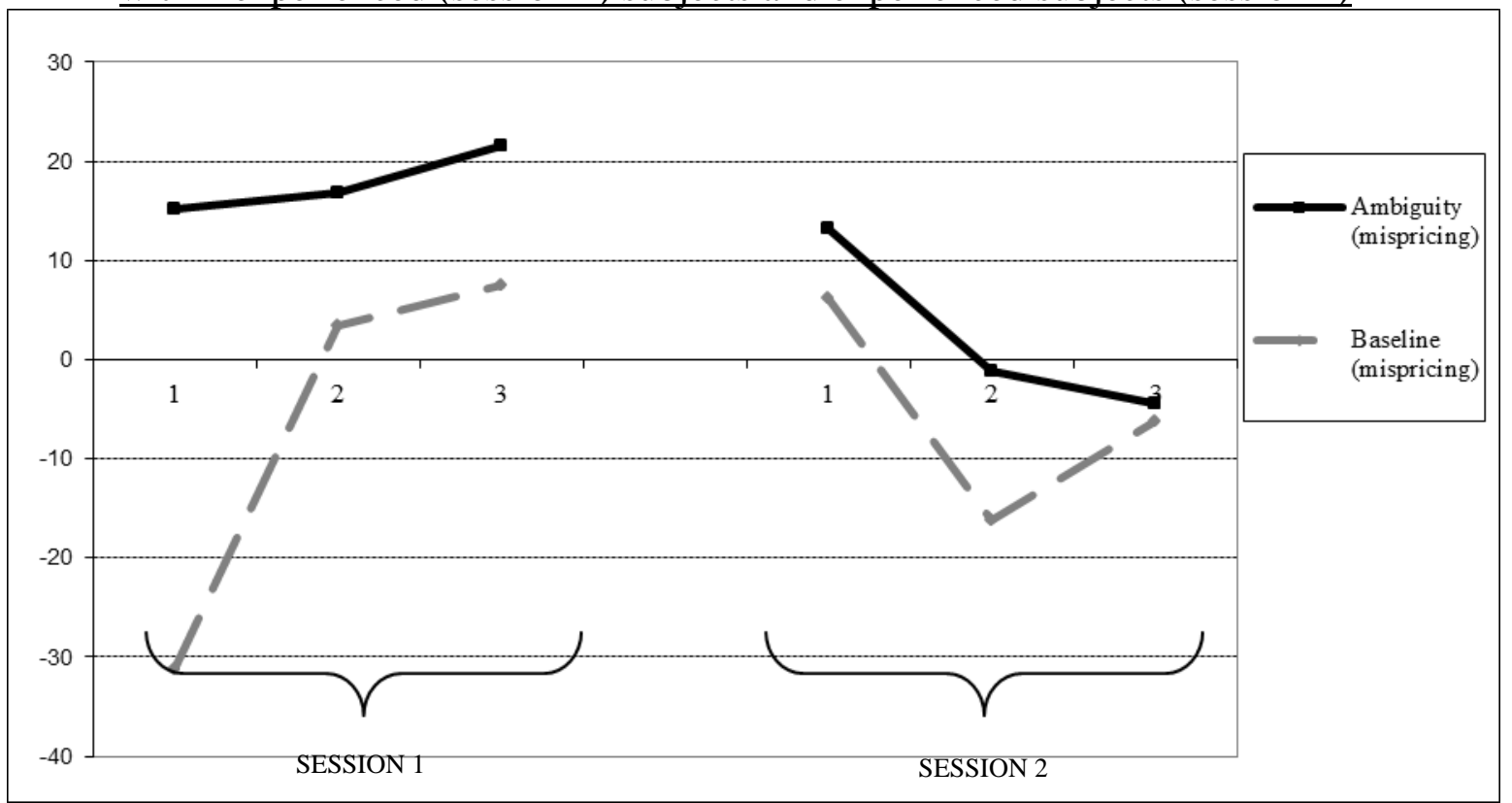

\section{$\underline{\text { II. Additional statistical analysis }}$}

\begin{tabular}{|c|c|c|c|}
\hline \multicolumn{4}{|c|}{ Inexperienced [experienced] traders (by treatments and periods) } \\
\hline & Period 2 & Period 3 & Total \\
\hline Baseline vs. Ambiguity & $\begin{array}{c}\mathrm{p} \text {-value }=1.000 \\
{[1.000]}\end{array}$ & $\begin{array}{c}\mathrm{p} \text {-value }=1.000 \\
{[0.386]}\end{array}$ & $\begin{array}{c}\mathrm{p} \text {-value }=0.910 \\
{[0.571]}\end{array}$ \\
\hline Inexperienced vs. experienced & $\mathrm{p}$-value $=1.000$ & $\mathrm{p}$-value $=0.521$ & \\
\hline
\end{tabular}

Table B.2: P-values for two-sided proportion tests of correct individual responses to news:

Inexperienced [experienced] traders (by treatments and periods)

\begin{tabular}{|c|c|c|c|}
\hline & Period 2 & Period 3 & Total \\
\hline \multirow{2}{*}{ Baseline vs. Ambiguity } & p-value $=0.57$ & p-value $=0.00^{* * *}$ & p-value $=0.00^{* * *}$ \\
& {$[0.74]$} & {$[0.02 * *]$} & {$\left[0.06^{*}\right]$} \\
\hline
\end{tabular}




\begin{tabular}{|c|c|c|c|c|}
\hline \multicolumn{4}{|c|}{ Table B.3: Probit estimates for inexperienced [experienced] traders: } \\
Dependent variables: correct trading responses $\left(\mathrm{CPR}_{i}\right), \mathrm{n}=89[\mathrm{n}=78]$
\end{tabular}

\begin{tabular}{|c|c|}
\hline \multicolumn{2}{|c|}{ Table B.4: P-values for two-sided tests comparing the proportion of price changes classified as under-reaction } \\
and over-reaction in the case of inexperienced [experienced] traders \\
\hline Baseline & Under-reaction \& Over-reaction \\
\hline Ambiguity & p-value $=1.00[0.343]$ \\
\hline \hline Aggregate (Baseline \& Ambiguity) & p-value $=1.000[1.000]$ \\
\hline
\end{tabular}

\begin{tabular}{|c|c|c|c|c|}
\hline \multicolumn{6}{|c|}{ Table B.5: Correlation matrix for the four individual measures of trading behavior } \\
\hline Correlations & $\begin{array}{c}\text { Basic } \\
\text { inconsistency }\end{array}$ & $\begin{array}{c}\text { Average } \\
\text { inconsistency }\end{array}$ & Extreme pricing & $\begin{array}{c}\text { Individual mispricing } \\
\text { behavior }\end{array}$ \\
\hline Basic inconsistency & 1.00 & - & - & - \\
\hline Average inconsistency & $0.63^{* * *}$ & 1.00 & - & - \\
\hline $\begin{array}{c}\text { Extreme pricing } \\
\text { Individual mispricing } \\
\text { behavior }\end{array}$ & $0.33^{* * *}$ & $0.47^{* * *}$ & 1.00 & 1.00 \\
\hline
\end{tabular}


Table B.6: P-values for two-sided Wilcoxon Rank Sum tests comparing different measures of individual trading behaviour between treatments and for inexperienced [experienced] traders

\begin{tabular}{|c|c|c|c|c|}
\hline \multicolumn{1}{c}{$\begin{array}{c}\text { Basic } \\
\text { inconsistency }\end{array}$} & $\begin{array}{c}\text { Average } \\
\text { inconsistency }\end{array}$ & Extreme pricing & $\begin{array}{c}\text { Individual mispricing } \\
\text { behavior }\end{array}$ \\
\hline $\begin{array}{c}\text { Baseline vs. } \\
\text { Ambiguity }\end{array}$ & $\mathrm{p}=0.030[0.402]$ & $\mathrm{p}=0.012[0.588]$ & $\mathrm{p}=0.000[0.340]$ & $\mathrm{p}=0.000[0.522]$ \\
\hline $\begin{array}{c}\text { Experienced vs. } \\
\text { Inexperienced }\end{array}$ & $\mathrm{p}=0.213$ & $\mathrm{p}=0.679$ & $\mathrm{p}=0.059$ & $\mathrm{p}=0.640$ \\
\hline
\end{tabular}




\section{$\underline{\text { Appendix C }}$}

Ambiguity sessions: time series of contract prices and fundamental value of the asset (horizontal lines) for all sessions. On the left panel, we display sessions with inexperienced subjects while sessions with experienced subjects are displayed on the right. Prices are displayed on the vertical axis and time on the horizontal axis.
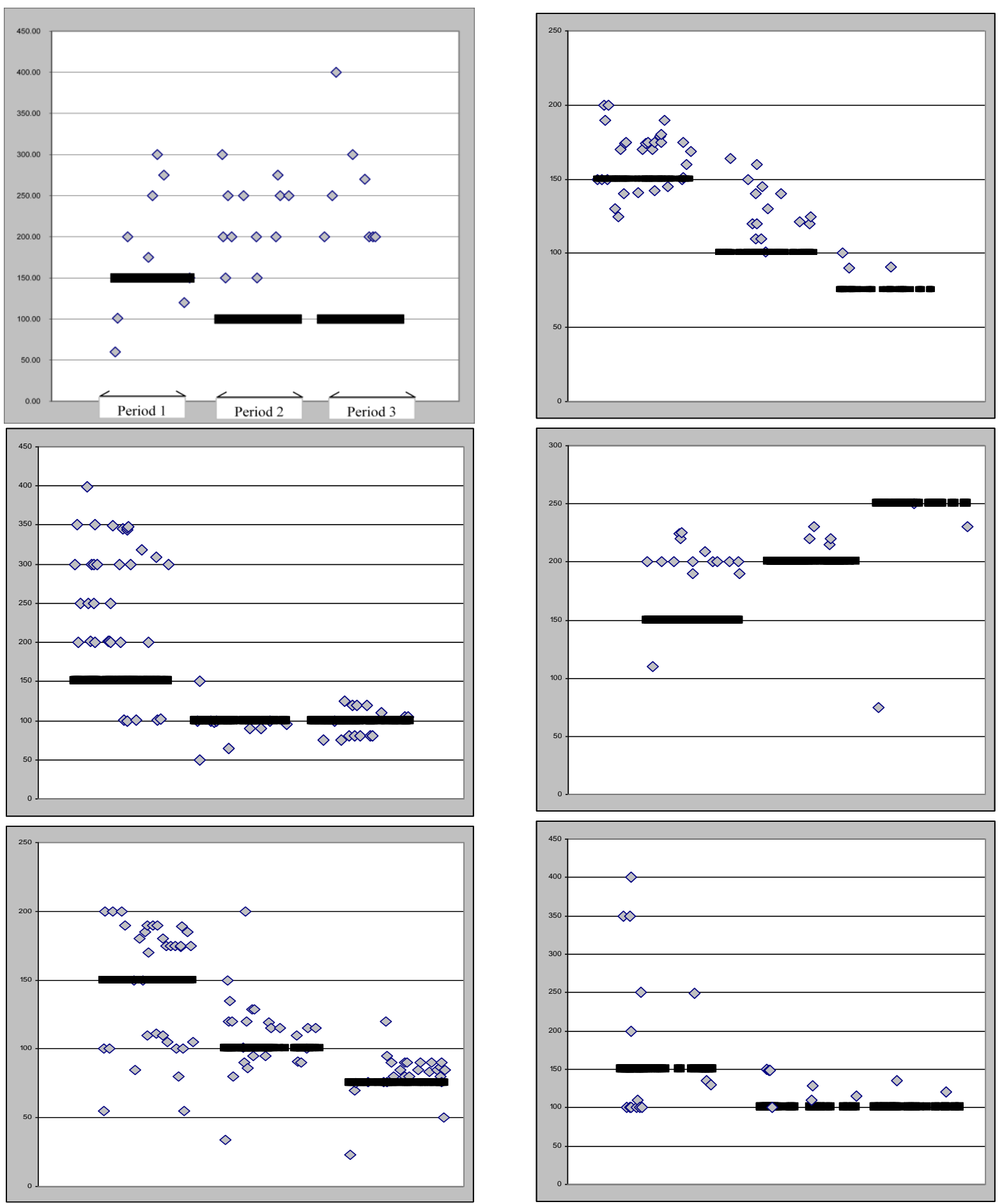

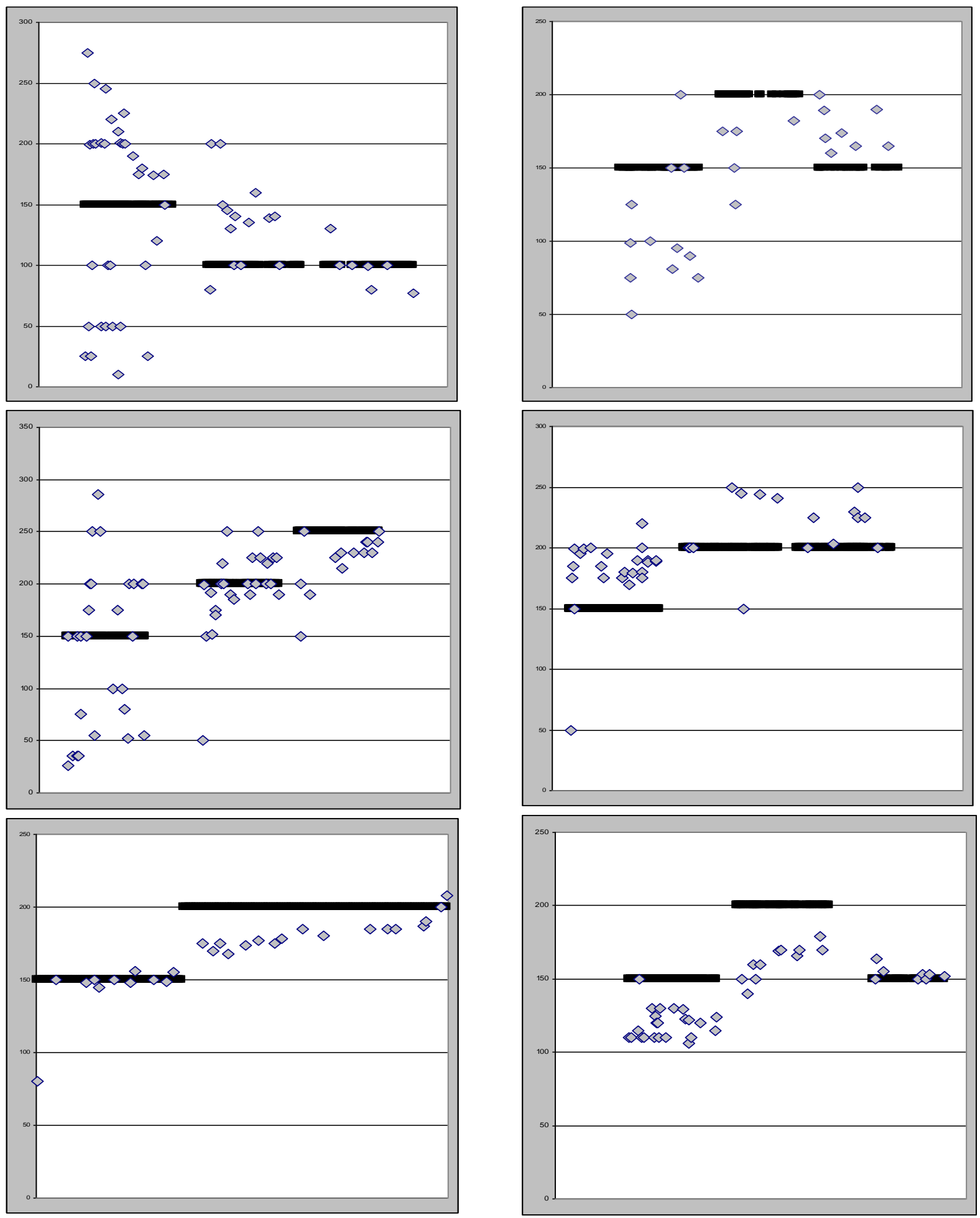
$\underline{\text { Baseline sessions: contract prices }}$
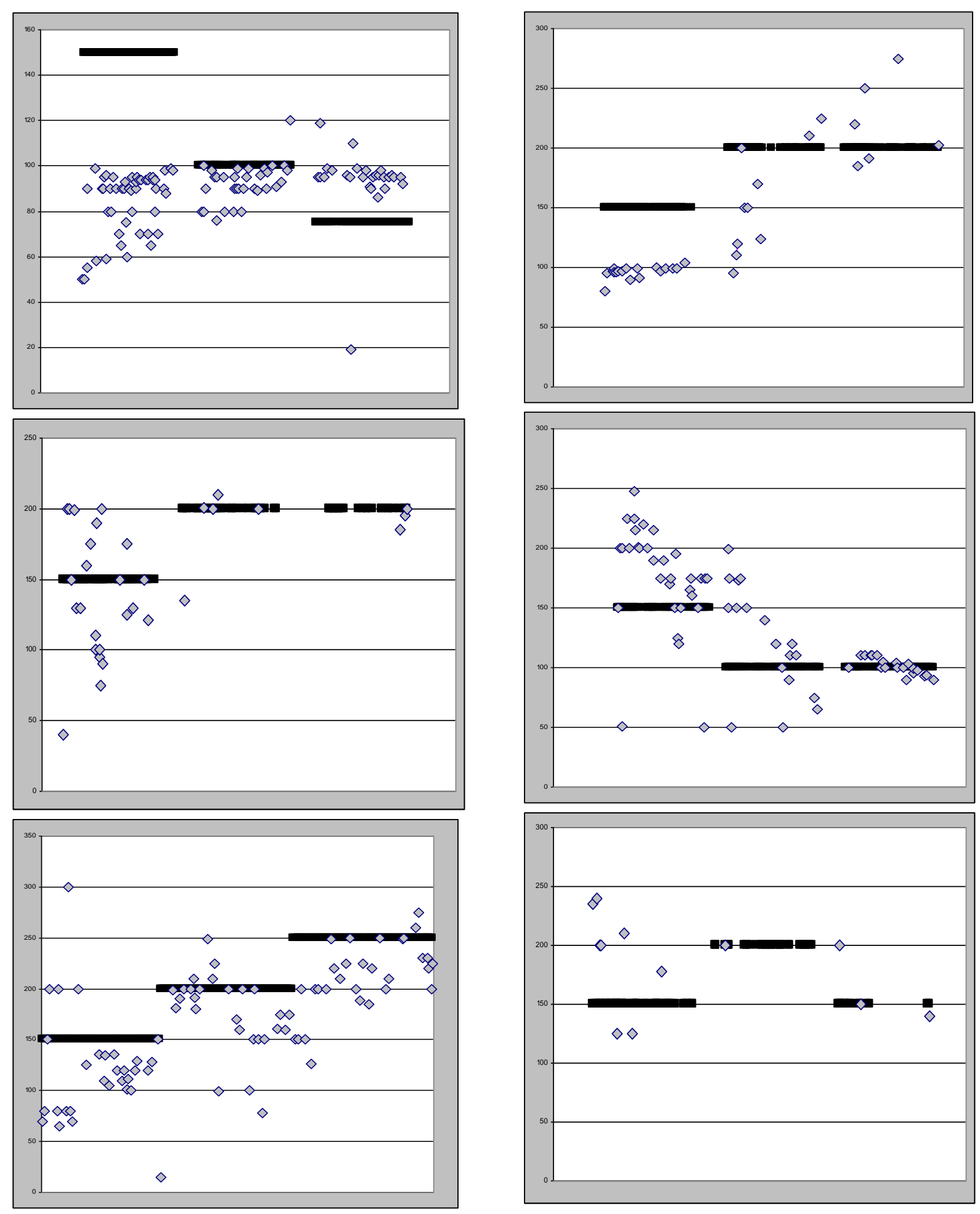

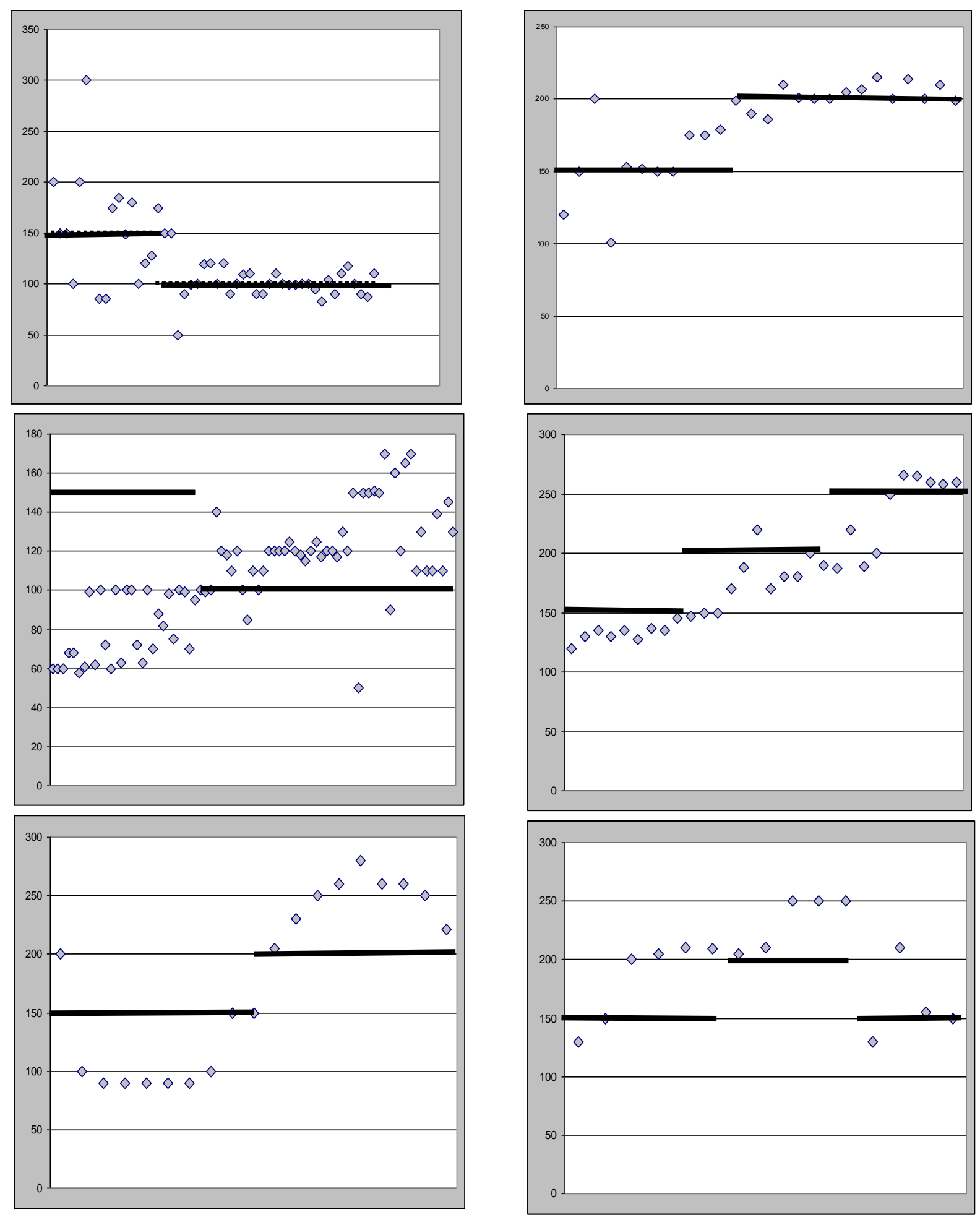


\section{Economic Science Institute Working Papers}

2010

10-22 Mago, S., Sheremeta, R., and Yates, A. Best-of-Three Contests: Experimental Evidence.

10-21 Kimbrough, E. and Sheremeta, R. Make Him an Offer He Can't Refuse: Avoiding Conflicts Through Side Payments.

10-20 Savikhim, A. and Sheremeta, R. Visibility of Contributions and Cost of Inflation: An Experiment on Public Goods.

10-19 Sheremeta, R. and Shields, T. Do Investors Trust or Simply Gamble?

10-18 Deck, C. and Sheremeta, R. Fight or Flight? Defending Against Sequential Attacks in the Game of Siege.

10-17 Deck, C., Lin, S. and Porter, D. Affecting Policy by Manipulating Prediction Markets:

Experimental Evidence.

10-16 Deck, C. and Kimbrough, E. Can Markets Save Lives? An Experimental Investigation of a Market for Organ Donations.

10-15 Deck, C., Lee, J. and Reyes, J. Personality and the Consistency of Risk Taking Behavior: Experimental Evidence.

10-14 Deck, C. and Nikiforakis, N. Perfect and Imperfect Real-Time Monitoring in a Minimum-Effort Game.

10-13 Deck, C. and Gu, J. Price Increasing Competition? Experimental Evidence.

10-12 Kovenock, D., Roberson, B.,and Sheremeta, R. The Attack and Defense of Weakest-Link Networks.

10-11 Wilson, B., Jaworski, T., Schurter, K. and Smyth, A. An Experimental Economic History of Whalers' Rules of Capture.

10-10 DeScioli, P. and Wilson, B. Mine and Thine: The Territorial Foundations of Human Property.

10-09 Cason, T., Masters, W. and Sheremeta, R. Entry into Winner-Take-All and Proportional-Prize Contests: An Experimental Study.

10-08 Savikhin, A. and Sheremeta, R. Simultaneous Decision-Making in Competitive and Cooperative Environments.

10-07 Chowdhury, S. and Sheremeta, R. A generalized Tullock contest.

10-06 Chowdhury, S. and Sheremeta, R. The Equivalence of Contests. 
10-05 Shields, T. Do Analysts Tell the Truth? Do Shareholders Listen? An Experimental Study of Analysts' Forecasts and Shareholder Reaction.

10-04 Lin, S. and Rassenti, S. Are Under- and Over-reaction the Same Matter? A Price Inertia based Account.

10-03 Lin, S. Gradual Information Diffusion and Asset Price Momentum.

10-02 Gjerstad, S. and Smith, V. Household expenditure cycles and economic cycles, 1920 - 2010.

10-01 Dickhaut, J., Lin, S., Porter, D. and Smith, V. Durability, Re-trading and Market Performance.

2009

09-11 Hazlett, T., Porter, D., Smith, V. Radio Spectrum and the Disruptive Clarity OF Ronald Coase.

09-10 Sheremeta, R. Expenditures and Information Disclosure in Two-Stage Political Contests.

09-09 Sheremeta, R. and Zhang, J. Can Groups Solve the Problem of Over-Bidding in Contests?

09-08 Sheremeta, R. and Zhang, J. Multi-Level Trust Game with "Insider" Communication.

09-07 Price, C. and Sheremeta, R. Endowment Effects in Contests.

09-06 Cason, T., Savikhin, A. and Sheremeta, R. Cooperation Spillovers in Coordination Games.

09-05 Sheremeta, R. Contest Design: An Experimental Investigation.

09-04 Sheremeta, R. Experimental Comparison of Multi-Stage and One-Stage Contests.

09-03 Smith, A., Skarbek, D., and Wilson, B. Anarchy, Groups, and Conflict: An Experiment on the Emergence of Protective Associations.

09-02 Jaworski, T. and Wilson, B. Go West Young Man: Self-selection and Endogenous Property Rights.

09-01 Gjerstad, S. Housing Market Price Tier Movements in an Expansion and Collapse.

2008

08-10 Dickhaut, J., Houser, D., Aimone, J., Tila, D. and Johnson, C. High Stakes Behavior with Low Payoffs: Inducing Preferences with Holt-Laury Gambles.

08-09 Stecher, J., Shields, T. and Dickhaut, J. Generating Ambiguity in the Laboratory.

08-08 Stecher, J., Lunawat, R., Pronin, K. and Dickhaut, J. Decision Making and Trade without Probabilities.

08-07 Dickhaut, J., Lungu, O., Smith, V., Xin, B. and Rustichini, A. A Neuronal Mechanism of Choice. 
08-06 Anctil, R., Dickhaut, J., Johnson, K., and Kanodia, C. Does Information Transparency Decrease Coordination Failure?

08-05 Tila, D. and Porter, D. Group Prediction in Information Markets With and Without Trading Information and Price Manipulation Incentives.

08-04 Caginalp, G., Hao, L., Porter, D. and Smith, V. Asset Market Reactions to News: An Experimental Study.

08-03 Thomas, C. and Wilson, B. Horizontal Product Differentiation in Auctions and Multilateral Negotiations.

08-02 Oprea, R., Wilson, B. and Zillante, A. War of Attrition: Evidence from a Laboratory Experiment on Market Exit.

08-01 Oprea, R., Porter, D., Hibbert, C., Hanson, R. and Tila, D. Can Manipulators Mislead Prediction Market Observers? 